\title{
Bir Manipülasyon ve Motivasyon Alanı Olarak Kentsel Ortam [Milieu] ${ }^{1}$
}

\author{
Duygu Ovacık Çoruh ${ }^{2}$ \\ ORCID: 0000-0002-2584-5312
}

\section{Öz}

Mekâna ilişkin modern bir bilgi alanı ve pratikler bütünü olarak mimarlık kendi üretim alanın biçimlendiren bir disiplin olmanın ötesinde, öznel deneyimi belirlemeye yönelik normatif stnırların üretimine katılır. Öte yandan mimarlık bir tasarım pratiğidir ki bu stnırlara karşı, yeni bir deneyim arayışı anlamında eleştirel eğilimleri üretmek durumundadır. Ancak mimarlığın eleştirel pozisyonu modern kapitalist kentle ilişkisi bağlamında tartışmalıdır. Bu anlamda güncel koşulların devamı; ama aynı zamanda tasarım pratiklerinin olană̆ından ayrılmayan bir mekân kavrayışı mümkün müdür? İnsan ve yaşam çevresinin bağlllaşık ilişkisinde temellenen 'ortam', bu soru bağlamında çalışmayı yapılandıran yöntemsel bir araçtır. Çalışma özelinde ortam, bilim ve felsefi tarihinde özel bir içeriğe sahip olan milieu kavramından türetilmektedir. Canguilhem, Foucault, Deleuze ve Guattari'nin metinlerine dayanan milieu, Foucault'nun modern özneleşme perspektifiyle bir arada ele alınarak ortama genişletilmektedir.

Çalışmada özne-nesne ayrımından değerler ve pratiklere hareket eden ortam aracılı̆̆ıyla, mekânsal pratiklerin stratejik etkileri sorunsallaştırılırken; tasarım pratiği yeni bir deneyimin üretim olană̆̆ olarak ortaya konulmaktadır. Böylece kentsel ortam, özel tarihsel koşullarda nesneleşme ve özneleş[tir]menin gerçekleştiği mekândır; ancak bu belirlenim bir kabul değildir. Performatif bir araç olarak ortam [medium], stratejik değer kategorilerinden, içinde bulunduğumuz şeyi; kenti 'çoğaltarak' sıyrılır. Böylece 'gerçek olan' normatif sınırlara karşı yenidenüretilebilir ki tarihsel sınırlar aşılabilir.

Anahtar Kelimeler: Ortam [milieu], pratik, değer, mimari tasarım, sınır-tutum.

\footnotetext{
${ }^{1}$ Bu makale Duygu Ovacık Çoruh tarafindan, İstanbul Teknik Üniversitesi Fen Bilimleri Enstitüsü Mimari Tasarım Programı'nda, Prof. Dr. Belkıs Uluoğlu danışmanlığında 2018 yılında tamamlanan "Kentsel ortam [milieu]: Özneleş[tir]meye yönelik manipülasyon ve 'karşı-özneleşme' pratiği için motivasyon alanı" adlı doktora tezi temel alınarak hazırlanmıştır.

${ }^{2}$ Arş. Gör. Dr., Erciyes Üniversitesi, E-mail: duyguovacik@gmail.com

idealkent @ Kent Araştırmaları Dergisi (Journal of Urban Studies)

http://idealkentdergisi.com

Geliş Tarihi Received Date: 19.06.2019 Kabul Tarihi Accepted Date: 31.12.2019
} 


\title{
Urban Milieu as a Space of Manipulation and Motivation
}

\author{
$*$ \\ Duygu Ovacık Çoruh ${ }^{3}$ \\ ORCID: 0000-0002-2584-5312
}

\begin{abstract}
In this study, the concept of milieu is understood as space that is based on the correlative relationship between human and the environment. In this context, the aim of the study is to assess the strategic effects of spatial practices in the process of defining the historical boundaries of subjective experience, and to demonstrate how the architectural design practices create new subjective experience opportunities against these boundaries. The milieu is constituted as a conceptual medium that configures this problematization process. In this study, the framework that the texts by Canguilhem, Foucault and Deleuze $\mathcal{E}$ Guattari provide to describe the concept of milieu were investigated together with the perspective of modernity, which Foucault defined as the 'subjectification' process.

In this regard, the city is considered as a space where possible problematization, objectification and subjectification are realized in unique historical conditions. However, this determination is not an acceptance; on the contrary, it can be reproduced in milieu design practices where historical boundaries can be transcended. Thus, the 'reality' can be reproduced against the normative boundaries, since milieu is the medium for new and different configurations.
\end{abstract}

Keywords: Milieu, practice, value, architectural design, critical-attitude.

\footnotetext{
${ }^{3}$ Research Asst., Erciyes University, E-mail: duyguovacik@gmail.com

idealkent @ Kent Araştırmaları Dergisi (Journal of Urban Studies)

http://idealkentdergisi.com

Geliş Tarihi Received Date: 19.06.2019 Kabul Tarihi Accepted Date: 31.12.2019
} 


\section{Giriş}

Mimarlık, tarihsel hakikatin sınırlarını belirleyen siyasi, ekonomik, toplumsal ve kültürel olaylar bütününün içinde modern bir bilgi alanı ve pratiktir. Bu bağlamda günümüzün küresel kapitalist dünyasına genişleyen mimarlık, öznel deneyimi belirlemeye yönelen normatif sınırların üretimine katılır. Öte yandan mimarlık mekâna ilişkin bir tasarım pratiğidir ki olası yapma biçimlerine karşı öznelliği; yeni bir deneyime yönelen eleştirel eğilimleri üretmek durumundadır. Dolayısıyla mimarlık, 'özneleşme' ve 'öznellik' olarak tanımlanabilecek iki konumu da içeren pratiklerin alanıdır.

Ancak modern mimarlığın tarihsel gerçeklikle kurduğu eleştirel ilişkisi tartışmalıdır. Bu bağlamda eleştirel bir pozisyonun olanağını savunan Hays (2015) ve Martin (2017), tartışmayı yirminci yüzyılın savaş-sonrası özel koşullarında bu pozisyonun olanaksızlığını savunan $\mathrm{M}$. Tafuri'nin çözümlemesi temelinde geliştirmişlerdir: Tafuri'ye göre mimarlığın eleştirdiği dışsal güçlerle, sistemin içinde kalmak üzere kurmak durumunda olduğu a priori iş birliği zorunludur ve bunun en önemli kanitı tarihsel avangarttr (Hays, 2015, s.3-4; Martin, 2017, s.325). Hays'e (2015, s.6-13) göre yirminci yüzyılın başında "devrimci/tarihsel avangart" 1 özne ve değerler sisteminden özerk hale gelen biçim dili, mimarlığın tarihsel düzene karşı durmasını sağlayan etkidir; ama aynı zamanda modern kapitalist kentle ilişkisi temelinde gerçeklikten sıyrılan bir mekân kavrayışına neden olmuştur. Aynı tarihsel perspektifte Tschumi'nin "Architecture and Transgression" metnini Vidler (1976, s.55) "yeni bir deneyim alanın açılmasına yönelik bir eleştiri için gereken araçları sağlayacak mı; yoksa yeni bir ütopya yapım aşamasında mı?" sorusu üzerinden tartışmıştır. Dolayısıyla yirminci yüzyılın sonunda mimarlığın araçsal pozisyonunu kabul etmek ya da yaşam pratiğinin dışına sürüklenmek durumunda olduğu bir çifte açmaz üzerinden tartışıldığı koşullar söz konusudur (Hays, 2015, s.4). Bu bağlamda da mimarlığın gerçeklikle ilişkisi giderek tasarım pratiklerinin arayışına yönelik bir olanaksızlık üzerinden değerlendirilmiş; mimarlığın önemini kaybettiği görüşüne neden olmuştur (Hays, 2015; Sykes, 2017).

Modern mimarlığın bu paradoksal pozisyonu daha genel bir modernlik perspektifinde değerlendirilebilmektedir. Bu bağlamda Calinescu'dan (1987, s.55) hareketle modernliği, kendi üzerine düşünen bilinçli bir tutum olarak tanımlamak mümkündür. Bu dönüşlü jest [reflexive] özneye ve fail olma durumuna işaret etmektedir ki modernlik aynı zamanda 'kurucu özne' kavrayışı ve dolayısıyla normatif bilgi üretimiyle de doğrudan ilişkili olmuştur (Fo- 
ucault, 2011a, s.176, 185-186). Bu bağlamda yeni bir deneyim olanağının, yaşamın dışında arandığı ve bilgi rejimlerinin olası eğilimleri belirlemeye yöneldiği bir modernlik tarif edilebilmektedir. Kwinter (2002, s.33-40) bu anlamda "klasik mekân boyutu"; öznel deneyimi belirleyen nesne kabulünden ve "klasik zaman boyutu"; aşkın bir özne konumundan hareket ederek belirli bir mimarlık yapma biçimini öngören iki eksen tanımlamıştır. Başka bir ifadeyle yaşamın olası eğilimlerinin çokluğu ve mimari temsilin çoğulcu biçimlerindense, mimarlığın modern söylem dilinin özne-nesne temel ayrımı üzerine kurulduğu iddia edilebilmektedir (Stoppani, 2006, s.155).

Bu okumadan hareketle çalışmanın amacı, mimarlık bilgi alanında hem tarihsel gerçeklikten kopuk olmayan hem de tasarım pratiklerinin olanağından ayrılmayan bir yaklaşımın geliştirilmesidir. Bu bağlamda modern kentsel koşullardan hareket eden ama aynı zamanda normatif üretim biçimlerine karşı eleştirel bir mimarlık pratiği mümkün müdür? Böyle bir pratikle birlikte mekân, üzerine düşünülen koşulların aynı zamanda yeniden-üretilebildiği diyagramatik bir araç olarak ele alınabilir mi? Mekânın eleştirel pratiklerin nesnesi olduğu bir yaklaşım, çalışmada mimari tasarım pratiğinin üretim olanağı olarak ele alınmaktadır ki 'ortam' bu doğrultuda oluşturulan bir mekân kavrayışıdır.

Bu bağlamda bir kavramsallaştırmayı oluşturmak üzere; mekânsal pratikler, özne, öznenin deneyimi, deneyimin nesnesini ayrı ayrı değerlendiren yaklaşımların dışına çıkarak, varoluşun ilişkisel yapısı içerisinde unsurların karşılıklı olarak kurulduğunu temel alan bir bakış açısıyla değerlendirilmektedir. Çalışmada özne ve mekân arasında ilişkisel ontolojik bir yaklaşım, Foucault'nun (1988) deneyimin tarihsel olarak kurulması sürecini açıkladığı modern özneleş[tir]me teorisi temelinde geliştirilmektedir. Bu perspektifte deneyimi belirleyen ne kendi başına bir nesne ne kendi başına bir öznedir, belirleyici olan birtakım pratiklerdir (Foucault, 2011d; 2011g). Bu pratiklerin ve dolayısıyla özne ve nesne biçimlerinin belirlenmesinin arkasında, Foucault'nun (2011e; 2013) “hakikat rejimi/oyunları” olarak tanımladığı süreçler vardır.

Bu çerçevede Keskin (2002) tarihsel deneyimin nasıl kurulduğu ile doğrudan ilişkili olarak bilimsel bilginin üretimini "sorunsallaştırmalar" olarak açıklamıştır. Keskin'in (2002) yorumundan hareketle, nesne ve öznenin birtakım pratikler aracılığıyla aynı anda karşılıklı olarak birbirlerini belirledikleri bir "hakikat rejimi" nin üretimini şu şekilde açıklamak mümkündür: Sorunsallaştırma sürecinde üzerine düşünülen şey söylemsel ve söylemsel olmayan birtakım pratiklere; Foucault'nun (2011e, s. 86) "söylem" olarak tanımladığı şeye maruz kalır ki söylem, üzerine düşünülen gerçekliğin hakikatini 
söylemeye başlar. Bu süreçte varlık ya da davranış biçimi bir düşünce nesnesi haline gelirken, deneyimin tarihsel sınırları belirlenmiş olur. İnsan, "kendilik pratikleri" ni tarihsel olarak belirlenen normatif sistemler üzerinden gerçekleştirdiğinde deneyimin öznesi pozisyonuna geçerek özneleşir (Foucault, 1988, s.10; 2011a, s.191).

Burada sorunsallaştırma ne var olan gerçekliği temsil etmek ne de olmayan bir şeyi icat etmek değil, varlığı tarihsel gerekliliklerin koşullandırdığ belirli bir söylemle eklemlendirmek anlamında kullanılmaktadır (Foucault, 2011e; Keskin, 2002). Dolayısıyla Foucault perspektifinden hareketle hakikatin olumsal ve bu bağlamda deneyimin tarihsel sınırlarının aşılabilir olduğu bir yaklaşım ortaya konulabilmektedir. Bu analizi aracilığıyla Foucault (2011a, s. 188), gerçekliğin öznel pratikler içinde çoğaltıldığı tarihsel-eleştirel bir tutumu "sınır-tutum" olarak önermiştir.

Bu çerçeve mimarlık bilgi alanının öznel eğilimleri içinde kentin bir problem ve analiz konusu olarak ortaya çıktı̆̆ 1 ve bu bağlamda gerçekliğin yeniden üretildiği kronolojik bir okumayı geliştirmektedir. Bu doğrultuda, Hays' in (2015) "geç avangart" olarak tarif ettiği, Aldo Rossi'nin "Şehir" kavrayışı teoriyi yaşam pratiğinin alanına taşırken; kenti de söylemde sorunsallaştırılan ve yeniden üretilebilen kavramsal düzeye taşıyan bir eksen değişimi olarak ele alınmaktadır. Bu bağlamda 60'lı yıllardan günümüze mimarlık nesnesinin diğer nesnelerle ve özneyle ilişkisi, önce kente sonra S. Allen'in (1999; 2017) değişiyle "alan koşulları" na [field conditions] genişletilebilmektedir.

Benzer bir okuma yirminci yüzyılın savaş sonrası koşullarında, özne ve nesne ilişkiselliğini temel alan eleştirel yaklaşımların mekânı ele alma biçiminde ortaya konulabilmektedir. Bu çerçevede G. Canguilhem' in (2001) canlı yaşamı ve çevre ilişkisinin değerler ve pratikler aracılığıyla bağlılaşık hale geldiği milieu kavramsallaştırması temel alınmaktadır. Deleuze ve Guattari'nin (1987) düşüncesinde ise tüm unsurların ilişkisel olarak bir arada bulunduğu mekân-zaman bloğu milieu olarak tanımlanmaktadır. Son olarak Foucault'nun (2013) "biyo-iktidar" analizi aracılığıyla modernlik ve kentleşme süreçleriyle birlikte bu bağlılaşık ilişkinin "yönetimsel" [governmentality] iktidar pratiklerine dâhil olduğu ve bu bağlamda milieu olarak ele alınan mekânın müdahalenin alanı olarak ortaya çıtığı bir kavramsallaştırma mümkün olmaktadır. Özne ve nesne ayrımından değerler ve pratiklere yönelen bu teorik çerçevede, özneleş[tir]me ve nesneleş[tir]me süreci olarak tarif edilen "yurtlanma" düzeylerinin sanat ve yaratıcıllğa açldığı üretici yaşam döngüsüne ait bir mekân kavrayışı mümkün olmaktadır. Son olarak, bu 
teorik çerçeve aracilığıyla mekânın hem öznenin eğilimlerini belirlemeye yönelen stratejik pratiklerle hem de yeni bir deneyime yönelik tasarım pratikleriyle yeniden üretilebilir bir araç haline geldiği güncel örnekler tartışılmaktadır.

Bu bağlamda çalışmada kentsel mekân, Foucault'nun (2011h, s.76) "çekişme" [agonisma] biçiminde tarif ettiği yaratıcı "oyun"un alanı olarak ele alınmaktadır. Böylece kentsel mekâna yönelik ayrım ve sınıflandırmalardansa kentlerin bir arada tuttukları ilişkiler ortaya konulabilmekte ve mimarlık bilgi alanında özne ve nesneden koşullara; değerler ve pratiklere yönelen bir bakış açısı geliştirilebilmektedir. Mekânı ele alınış biçiminde ortaya çıkan varoluşsal farklılık, mekânsal müdahalenin koşullarını ve tasarım pratiklerinin araçlarını belirlemektedir.

\section{Yöntem}

Çalışmanın ilişkisel ontolojik yaklaşımı, felsefi bir tavır olarak teorik içeriğini ve yöntemini belirlemektedir. Bu yaklaşım temelinde çalışmada literatür taraması ve gömülü teori araştırma modeli kullanılmaktadır. Mimarlığa ve milieu kavramına ilişkin teorik içeriğin sağladığı ve sınırladığı çerçeve, modern özneleş[tir]me perspektifiyle yeniden üretilerek bir kavramsal model geliştirilmektedir.

Bu bağlamda milieu kavramından türetilen ortam, mimarlık bilgi alanında diyagramatik doğaya sahip bir mekân kavrayışıdır. Tersten bir okumayla ortam olarak ele alınan kentsel koşulların çeşitli pratikler içinde yeniden-üretim olanağı, milieu kavramına ilişkin içerik ve Foucault'nun modernlik perspektifine dayanmaktadır.

Fransızca kökenli milieu, İngilizcede aynen kullanılmakla birlikte'surroundings', 'medium' ve 'middle' gibi farklı alanlarda farklı sözcüklerle çevrilebilmektedir. Bilim ve felsefe tarihinde üç anlamının da birleştiği özel bir içerik kazanmış olan milieu kavramı bu bağlamda 'environment' (çevre) sözcügünden de farklılaşmaktadır: İngilizce 'environment' sözcügü Türkçede 'çevre' (dışarısı) kategorisine karşılık gelirken, 'milieu' sözcüğü için canlı ve çevresini ilişkisel olarak düşündüren 'ortam' sözcüğü kullanılmaktadır (Türk Dil Kurumu, Güncel Türkçe Sözlük, [TDK], 2017). Çalışmada Canguilhem, Foucault ve Deleuze-Guattari'nin orijinal metinlerine gönderme yaparken doğrudan 'milieu' sözcüğü ya da 'ortam [milieu]' olarak kullanılmaktadır. 


\section{Özne ya da Nesneden Alan Koşullarna}

Bu çalışmada ortam kavramsallaştırması, savaş sonrasının özel koşullarında ortaya çıkan eleştirel düşüncelerin yarattığı eksen değişiminde temellendirilmektedir. Bu bağlamda ilk olarak mimarlıkta 1960'l1 y1llarda başlayıp 1990'lı yıllara uzanan soyut kavramsal araçlarla başka bir mimarlık olanağını ortaya koymaya yönelen eleştirel teori temelli eğilimler ve Hays (2017) tarafından "atmosfer mimarlı̆̆g" olarak tanımlanan 1990 sonrasının pratikleri ortaya konulmaktadır. İkinci olarak milieu kavramının içeriği sunulmaktadır.

\section{Mimarlık Bilgi Alanında Eksen Değişimi}

Modern bir bilgi alanı olarak mimarlığın pratiğine ilişkin sorular, her durumda 'kural' koyma ve yapma biçimlerini belirlemeye yönelik bir istekten değil, deneyimin tarihsel sınırlarına karşı özgür bir başlangıç arayışından kaynaklanabilmektedir. Bu bağlamda Kwinter (2002) ne yalnızca öznenin yorumuna ne de çıkarımına bağlı olmayan, modernliğin "klasik zaman ve mekân" yaklaşımlarından ayrılan bir ekseni "radikal perspektivizm" olarak tanımlamıştır: Bu alan içerisinde özne ve nesne aşkın olarak değil bir arada üretilmiş etki olarak bulunurlar. "Şeyler" ve olaylar artık ilişkisel bir düzlemde olmak dışında başka hiçbir yerde olmama ilkelerine kavuşurlar (Kwinter, 2002, s.40). Bu bağlamda Kwinter (2002, s.34) modernliği tüm tarihsel akımların ve -daha sonra araçsal hale gelmiş olsa da- deneysel temelleriyle avangardın "olasılık alanı" olarak tanımlamıştır.

Dolayısıyla mimarlığın ontolojik değerlendirmesi, modernliğin rasyonalizminin çerçevelediği sınırlar içinde kalma zorunluluğu anlamında bir son olarak değil; sınırda olmak gerekliliği pratiğin araçları ve yöntemleri üzerine bir arayışın alanı olarak ele alınabilmektedir. Öyle ki mimarlık, Foucault'nun (2011a, s.181-184) düşüncesinde tarihsel düzen ve öznellik pratikleri arasındaki "çekişme" yi ve "felsefi döngü"yü mümkün kılabilecek bir tasarım alanı olarak değerlendirilebilir. Bu bağlamda mimarlığın koşullarla ilişkisi bir açmaz üzerinden değil, güncel ve eleştirel bir tutumun üretilmesi gerekliliği üzerinden ele alınmaktadır. Yirminci yüzyılın savaş-sonrası özel koşulları mimarlık bilgi alanında bu arayışın hâkim olduğu, Kwinter'ın "tarihsel kopma" ve Megill'in "kriz" sözcüğüyle nitelendirdiği, belirli bir tarihsel anı ortaya çıkarmıştır (Kwinter, 2002, s.34; Megill, 2008, s.13).

Bu bağlamda Sykes (2017, s.15) büyüyen tüketim toplumunun belirlediği tarihsel koşullarda mimarlığın ideolojik-temsili bağlarını ve rolünü mimarlık için bir alan yaratma çabasıyla sorgulayan eleştirel teori temelli eğilimleri, 
1960'li yıllarda başlayan bir hareketlenme olarak belirlemiştir. Hays (2015, s.3) ise "geç avangart/savaş sonrası avangart" okuması aracilığıyla mimarlık teorisinin [öz]eleştirel olarak kendi içine döndüğü görüşünü geliştirmiştir. Hays'e göre Aldo Rossi'nin tipoloji mantığı, Peter Eisenman'ın çerçeveleri, düzlemleri ve ızgaraları, John Hejduk'un duvarı ve Bernard Tschumi'nin sinegramatik kesitleri kapitalist kentsel koşulların öngördügü yapma biçimlerine karşı eleştirel bir öz-bilincin ürettiği felsefi pratiklerdir (Hays, 2015, s.2).

Bu okumadan hareketle Rossi'nin tipolojik düşünme biçimi, mimarlıkta bir eksen değişimi olarak ele alınabilmektedir. Hays'e göre Rossi, 1966 tarihli "Şehrin Mimarlığı" kitabında tipoloji aracılığıyla şehri mimarlığın zorunluluğu olarak kavramsallaştırarak ve tarihi güncelliğin içine dâhil ederek yaşam pratiğini kavramsal bir düzeye genişletmiştir (Hays, 2015, s.14,44). Burada "Şehir", Hays'in ifadesiyle "duygu durumlarl, atmosferler ve duygulanımlar yaratan saf bir gücüllük [virtuality] ağıdır" (Hays, 2015, s.33). Bu kavramsallaştırmaya olanak veren şey ise tipoloji mantığını kuran iki farklı türde zaman anlayışının; artsüremli ve eşsüremli zamanın birleşimidir (Hays, 2015, s. 32). Böylece simgesel bir "ifade alanı" aracılığıyla nesne, yalnızca mekâna ya da yalnızca zamana değil her ikisine birden yayılarak biçimin "olanaklılık koşulu" haline gelir (Hays, 2015, s.41-42). Bu yaklaşımla mimari nesne, "Şehir" denilen kendine özgü ilişkiselliğin içinde dolayımlı hale getirilir ki bu dolayım aynı zamanda tarihsel gerekliliklerin öngördüğü deneyim biçimine müdahale etmenin yolu olarak ele alınabilmektedir. Rossi, geçmişten geleni -özneye ilişkin değer kategorilerini- biçimin içine ve güncel olanı "Şehir" dediği zorunlu yapının içine doğru genişleterek, nesnenin kendi başına var olma hakkını elinden almıştır (Hays, 2015, s.44-47).

Daha genel bir perspektifte Hays'in $(2015$, s.3) "söylem çağında mimarlı" olarak ele aldığ1 bu dönem Tschumi'ye (1976, s. 57-58) göre, tipler ve modeller gibi mimarlığın kendi tarihi ve diline, dolayısıyla yaşam pratiğine işaret eden kavramları yeniden gündeme getirmiştir. Bu bağlamda 1990'lı yıllara kadar gelişen tarihsel eleştirel bir harekete Hays'i da dahil etmek gerekmektedir. Baird (2004) bu hareket içinde Hays'in ve Eisenman'ın "eleştirellik" ve "olumsuzlama" kavramları üzerine odaklanan baskın bir pozisyonu geliştirdiklerini ifade etmiştir. 1984 yılında "Critical Architecture: Between Culture and Form" isimli makalesinde Hays, tarihsellik ve disiplin arasında "eleştirel bir mimarlık" olasılığını, modernist arayışı gerçekleştiren tarihsel avangartta temellendirmiştir (Baird, 2004; Somol ve Whiting, 2017, s.178). Bu bağlamda "söylem çağında mimarlık" rasyonelleştirmeye yönelen toplumsal kodlar ve 
sistemlere karşı, tarihsel kapitalist sınırların sorgulandığı disipliner olarak eleştirel yaklaşımları içerir (Hays, 2015).

Tarihsel bir süreçte nesnenin, koşulların devamı olan aracı bir madde ve bir etki olarak kente genişlediği ama aynı zamanda on dokuzuncu yüzyılın başından bu yana modern mimarlık olarak ortaya çıan disiplinin çözülmesine neden olduğu düşüncesi ortaya konulabilmektedir. Bu anlamda Speaks (2017, s.194-195) "teori temelli öncüller" olarak tanımladığı 1960'lar ve 70'lerin eğilimlerinin sürekli olarak karşıt konumda olduklarını, sonuçta Modernizm ve gerçeklik arasına sıkışarak eleştirdikleri Modernizm ile aynı kaderi paylaştıkların iddia etmiştir. Speaks'e göre esnek birikime geçişin getirdiği rekabetçi koşulları ve yenilikleri fark etme konusundaki başarısızlık, yirminci yüzyılın sonunda teorinin tükenişinin nedenidir.

Bu bağlamda 1990'lardan itibaren mimarlık bilgi alanına, soyut kavramsal süreçlerin maddi pratiklerle bağını eleştiren ve pratiğin inşa gerekçelerine odaklanan, Speaks'in "öncüller-sonrası" [post-vanguards] mimarlığı olarak tanımladığı, eğilimler hâkim olmuştur (Speaks, 2017, s.196). Sykes (2017, s.19-20) yenilik arayışına yönelen bu eğilimleri "teknoyönetselciler", "eleştirel-sonrasıcllar" ve "yeni-pragmatistler" olarak gruplandırmıştır. Bu bağlamda yüzyıl dönümünde mimarlık bilgi alanını, maddi pratiklerin konu edildiği çalışmaların biçimlendirdiği iddia edilebilir ki öne çıkan temanın, pratiğin sonuçlarını ve toplumsal etkilerini önceden kurma/öngörme biçimi anlamında, projektif pratikleri üretmek olduğu değerlendirmesi yapılabilmektedir (Sykes, 2017).

Ancak Hays'in (2017, s.441) "yeni paradigma" olarak tanımladığı şey yalnızca yenilik arayışından kaynaklanmaz. Öyle ki yeni paradigma sayısal çağın araştırma alanları, nesne üretimi anlamında yeni olasılıkları sunarken, tasarımın konvansiyonel biçimlerini ve üretimlerini sorgulamaktadır. Bu bağlamda Sykes'e (2017, s.29) göre, Greg Lynn 1993 tarihli “Architectural Curvilinearity: The Folded, the Pliant, and the Supple" metninde, bir dizi farklı kaynağı mimarlığın teorik üretimine alternatif sunmak üzere ilişkilendirmiştir. Aynı bağlamda Sykes'e (2017, s.109) göre Allen de tarihsel etkilerin hem ürünü ama aynı zamanda onlara cevap veren; öznenin deneyiminin tamamen belirlenmiş olması yerine değişim olanağını içeren "alan koşullarına dayılı bir mimarlık" önermiştir. Allen'in (1999; 2017) "alan koşulları" olarak ele aldığ1 sayısal teknolojiler, iletişim ve enformasyon sistem ve ağlarıyla kullanıc davranışlarıdır. Bu bağlamda "alan koşulları, birden çoğa, bireylerden kolektivitelere, nesnelerden alanlara hareket eder" (Allen, 1999, s.92). Hays'in (2017, 
s.441) "atmosferik" kavramıla ifade ettiği bu yeni mimarlık, bir taraftan pratiğini yeni olanaklara açarken aynı zamanda nesneden ya da özneden çok koşullar ve kuvvetler üzerine düşünen bir teoriyi ortaya çkarmıştır.

Bu bağlamda yirmi birinci yüzyılda mimarlığın hesaplaşması gereken koşulların disiplinin sınırlarından gerçekliğin tarihsel düzlemine genişlediği iddia edilebilmektedir. Bu durum mimarlığın kendinden farklı başka bir sisteme araç kılınmasından ziyade üretildiği karmaşık koşullara gönderme yapar ve onları yeniden düzenler. Dolayısıyla disiplinin sınırları genişlerken, mimarlığın deneyimiyle birlikte eleştirel uğraşını da başka bir düzeye taşıdığı iddia edilebilmektedir. Sykes (2017, s.27) mimarlığın bu genişleyen kapsamına verilebilecek "paradigmatik örneği", mimari tasarım pratiği ve Manhattan üzerine kitabiyla R. Koolhaas olarak belirlemiştir. Baird'e (2004, s.1819) göre de Koolhaas, "uygulamanın yaratıcı metotları'na ve post-eleştirel gündemin diğer parçalarına gösterdiği ilgiye rağmen yine de güçlü eleştirel angajmanlara katılmıştır". Bu bağlamda Somol ve Whiting'in (2017, s.182183) ifadesiyle 1970 'li yıllardan itibaren "özerklik ve süreç olarak disiplinerlik"; 1990'lı yıllardan itibaren "güç ve etki olarak" tasarıma katkıda bulunan mimarlık vizyonlarına parçalanmıştır. Dolayısıyla süreç, eleştirinin pratiklerin etkilerinden doğan bir mimarlıkla da mümkün olduğu biçimlerini geliştirmiştir. Tarihsel koşulların içinde bu türden bir mimarlık aynı zamanda araçlarını bu gerçeklikten çıkarmak durumundadır. Bu anlamda mimarlık, yirminci yüzyılın ikincisi yarısından itibaren hem kentsel koşullara hem de, dil içinde ve dil içinde olmayan pratiklerin birleştiği şey olarak tanımlarsak, söyleme doğru açılmıştır.

Bu bağlamda gereksinime yönelik nesne üreten bir pratik olmasının ötesinde, yeni bir deneyim arayışı anlamında tasarım pratiğinin üretim olanağı, mimarlığın tarihsel sınırlarla eleştirel ilişkisinde aranmaktadır. Tschumi (1976) ortaya çıkan paradoksu şöyle ifade etmiştir:

Mimari, sadece kendisini inkâr ettiği yerde 'erotik' kapasitesi içinde hayatta kalabilir gibi görünür, toplumun kendisinden beklediği formu inkâr ederek kendi paradoksal mahiyetini aştığ yerde. Başka bir ifadeyle, bu bir imha ya da 'avangart' devrim değil, sınır aşımıdır (s.60).

Bu okuma aracılığıyla disiplinler sınırların yok olduğu günümüz koşullarının temel bir ayrımı ortaya koyduğu iddia edilebilmektedir: Tarihsel deneyimin sınırların kabul ederek normatif değer sistemlerinin üretimine katılmak yani özneleş[tir]me ya da bu sınırların eleştirisini mümkün hale getirecek bir arayışı, dolayısıyla sınır-tutumu üretmek üzere koşullarla ilişkilenmek. 


\section{Milieu}

Milieu sözcüğünün etimolojisi anlamını çözmenin iki yolunu ortaya çıartmaktadır: Mi-lieu sözcüğünün 'lieu' kökü bir canlıyı destekleyen sınırlı bir alanı imlemektedir ki canlı alanından ayrı düşünülür (Chien, 2006, s. 62). Öte yandan ' mi-' önekiyle birlikte, canlıyı mevcut konumunun ötesine geçen yeni bir "aracı alan" oluşturmak üzere vücudunu sürekli genişletirken hayal etmek mümkündür (Chien, 2006, s.62). İlk durumda canlı ve çevresi ayrı ayrı düşünülebilecek iki varlık kategorisi olarak ortaya çıkmaktadır; ikinci durumda ise her bir işlevsel döngünün üst üste binebileceği anlamında "birey-ötesi" [trans-individual] bir alandır (Chien, 2006, s.63). Bu ikinci anlam, milieu kavramınn yirminci yüzyılda çeşitli kullanımlarının genel felsefi etkisini belirlemiştir.

"Aracı alanlar" teorisiyle Canguilhem (2001, s.25), canlı ve koşulları arasında bağlılaşık bir ilişki tanımlamıştır. Bu ilişkide canlının eğilimi etki-tepki ilişkisinden ziyade, belirli bir değere ve öneme sahip bir dizi uyarana yönelik yorumlamalardır. Dolayısıyla bir ortamda [milieu] fiziksel uyaranların etkili olabilmesi için yalnızca üretilmesi yetmez, aynı zamanda fark edilmesi de gerekir. Canguilhem'e (2001, s.16-20) göre bu iletişim ilişkisinin temelinde gereksinim vardır ve yönelim biçimini belirleyen şey, canlının geri planda sahip olduğu değerler sistemidir. Bu bağlamda Canguilhem'in düşüncesinde milieu, önceden yapılandırılmış olmayan; ancak değerler, gereksinimler ve eğilimler aracılığıyla "kendini yapılandıran" varoluşa ait bir mekân kavrayışıdır. Sürekli yapılandırılmakta olan bu işlevsel döngüler, Canguilhem'e (2001, s.26) göre canlı için yaşamın anlamıdır.

Çeşitli döngüler üzerinden bağlılaşık hale gelen bu ilişkisellik doğal olarak yapılandırıcıdır. Bu bağlamda Deleuze ve Guattari (1987) ortamı [milieu], "sonuçsuz, gücül bir boşluk olarak" tanımladıkları "kaos"tan sonra gelen, yönlü bileşenlerin bir parça düzenle birlikte yeniden gruplandı̆̆ı "mekân-zaman bloğu" olarak tanımlamışlardır: "Şimdi evdeyiz. (...) Sinırları olan bir mekân üretmek için o bilinmez ve kırılgan merkezin etrafında bir daire çizmek gerekir" (Deleuze ve Guattari, 1987, s.311). Bu bağlamda ortamın [milieu] unsurlarını biçimlendiren eylemi söz konusudur ki yurtlanma olarak tanımlanabilecek bu süreçte dış dünyadan herhangi bir şey, içeriye yeniden kodlanarak alınır (Deleuze ve Guattari, 1987, s.321). Kaosa direnen bu eylem, Deleuze ve Guattari' nin düşüncelerinde "ortam gücü" [umwelt] olarak ortaya çıkmıştır (Ballantyne, 2010, s.85). Biçimlendirici yurtlanmaya karar veren ortam gücü, işlevsel döngülerin karşılaşmasının, dolasıyla ortamların iç içe geçmesinin sonucudur (Deleuze ve Guattari, 1987, s.51, 317, 321). Bu bağlamda 
Deleuze ve Guattari'ye (1987, s.311-313) göre yurtlanmada çeşitli bileşenlerin, sınır çizgilerinin ve işaretlerin rolü vardır. "Kontrpuan" olarak tanımlanan bu sınır çizgileri, ilişkileri bir araya getirerek mekân-zaman bloklarını heterojenleştirir (Deleuze ve Guattari, 1987, s.314). Bu anlamda ortamlar [milieus] ilişik, bileşik, bağlılaşık hale gelir.

Bu heterojen koşullarda yurtlanma, çoğul ilişki kurma biçimlerinin ortaya çıkardığı bir 'ifade gücü' olarak tanımlanabilir. Burada Deleuze ve Guattari'nin ritim dedikleri, etkileşim ve gerilim söz konusudur ki ortamların [milieus] bileşenlerinin periyodik hale gelen tekrarı, trans-kodlamalar veya geçişlerle "fark" 1 n üretimine katılabilir (Deleuze ve Guattari, 1987, s.314). Dolayısıyla ifade gücü bir taraftan unsurları biçimlendirirken; aynı zamanda kendiliğinden bir hareketi, ritmi ortaya çıkarabilmektedir. Bu hareketle birlikte ortamın gücünü oluşturan bilindik yollar, daire; farklı ilmekler, bağlar, hareketlerle birlikte "kaçış çizgileri" boyunca devinimli başka çizgilere dönüşür (Deleuze ve Guattari, 1987, s.311). Sürekli yapılandırılmakta olan böyle bir ilişkide yüzeye çıan "organik oluşum"; söz gelimi yapı, ev, bir kentin kurulması, farklı ortamların [milieus] çok çeşitli bileşen ve kuvvetlerini, seçme, eleme ve çıkartma işlemiyle tek bir bağlam içinde toplanması olarak ele alınabilir. Bu bağlamda "oluşum" basit bir yapı değildir, "yapılaştırmadır" ki tâbi olduğu ortamın [milieu] kuvvetlerini çoğaltır (Deleuze ve Guattari, 1987, s.51).

Ballantyne'a (2010, s.103) göre Deleuze ve Guattari'nin düşüncelerinde ifade gücü hem ötesine geçmeyi önerdikleri şey, yani sağduyunun ve alışkanların yapılandırıcı dünyası hem de yaratıcı faaliyetin kökenidir. Bu bakış açısını kente uygulamak mümkündür. Kent, Deleuze ve Guattari'nin düşüncelerinde gücül kuvvetlerin yer aldığı "içkinlik düzlemi" olarak ortaya çımiştır ki kentler de kendi özel koşullarıyla bir ortam gücü oluştururlar (Deleuze ve Guattari, 1987, s.431-434; Ballantyne, 2010, s.84).

Dolayısıyla insan ve yaşam ortamı olarak kent de bu bağlılaşık ilişki kavrayışının dışında kalmaz. Ancak insan ve kent söz konusu olduğunda bu ilişki karmaşıktır; çünkü insan öznesinin yaşam ortamı [milieu] aynı zamanda insanın "kendi olasılıklarını ve gereksinimlerini oluşturabildiği bir alandır" (Canguilhem, 2001, s.19). Tam da bu noktada bu ilişkisellik aynı zamanda manipülasyona yönelik pratiklerin alanına dönüş̧ebilmektedir. Bu bağlamda bir aracı alan olarak mekân teorisi Foucault'nun "biyo-iktidar" tezine bağlanabilmektedir. 


\section{Özneleş[tir]meye Yönelik Bir Müdahale Alanı Olarak Milieu}

Foucault'nun iktidar teknikleri analizinde milieu, bu bağlılaşık ilişkinin yönetimsel iktidar stratejisine dâhil oluşunu açılayan mekân terimidir. Milieu kavramının bu bağlamda kullanımı, daha genel bir analiz üzerinden anlaşllabilmektedir. Yönetimsellik, Foucault'nun "insan türünün temel biyolojik özelliklerini oluşturan şeylerin bir politikaya (...) dâhil olmalarını sağlayan mekanizmaların bütünü" (Foucault, 2013, s.3) şeklinde tanımladığı biyo-iktidar analizinde bir aşama olarak ortaya çıkmaktadır. Yaşam üzerine gelişen iktidar modelinin mekânı ele alma biçiminde ortaya çıkan temel bir dönüşüm 'şehir sorunu' [mekân] ve modern özneleş[tir]me [insan-nüfus] süreci üzerinden açılanabilmektedir.

On sekizinci yüzyılda ortaya çıkan kentleşme süreçlerini, idari devletlerin ve sınır ötesi ticaretin gelişimine bağlı olarak fiziksel sınırları belirli ve kontrollü bir mekânsal yapılanmadan, dolaşımlara açılmak üzere sürekli büyümeyi öngören bir kentsel yapılanmaya geçiş olarak özetlemek mümkündür (Foucault, 2013, s.13-14). Bu, yalnızca malların değil, insanların, fikirlerin, istençlerin dolaşımlarını sağlamaya ve sürekli yeni döngülere açılmayı gerektirmiştir (Foucault, 2013, s.20). Bu anlamda "şehir sorunu" Foucault'ya göre asıl sorunun ta kendisidir: "Şehrin yeni gelişme imkânları, hâlihazırda mevcut olan bir plana nasıl dâhil edilecek?" (Foucault, 2013, s.20, 57-58).

Kentleşmeyle birlikte ortaya çıkan sorunların ele alınış biçimi, ekonomipolitik olarak tanımlanabilecek yeni bir politik analizle ilişkilidir. Foucault'ya (2013, s.46-47) göre, ekonomi-politiğin olayı ele alma biçimi, yani liberalizm denilen şey gerçekliğin kendi fiili sürecinde akmasını sağlamaktır. Bu bağlamda bir takım analizlerle "gerçeklik öğesi" üzerine çalışan ve işlevsel döngüleri düzenlemeye yönelik yeni bir "iktidar aklı"nın mekânı ele alış biçimini Foucault milieu olarak tanımlamıştır: Milieu, "rastlantısal öğe dizelerinin içinde olup bittiği", ancak "geleceğin ve olasılığın da dâhil olduğu" bir mekân kavrayışıdır (Foucault, 2013, s.46-48).

Burada bir öğeler ve süreçler toplamı olarak kullanılan olayın/mekânın öznesi insandır ve milieu insanların tutumların belirlemeye yönelik bir müdahale alanıdır. Ancak bu noktada şu soruya cevap vermek gerekmektedir: Eğilimlerinin çeşitliliği anlamında bir olasılık alanı olan insanın tutumları milieu aracılığıyla nasıl manipüle edilebilmektedir?

Bu sorunun cevabı; söylemsel pratikler, söylemsel olmayan pratikler ve kendilik pratikleri eksenlerinde gelişen modern özneleş[tir]me süreciyle doğrudan ilişkilendirilebilmektedir. Öyle ki burada insan, "kolektif bir özne" ola- 
rak nüfus düzleminde ele alınmaktadır ve modern bilgi alanları içinde insanın nüfus düzeyinde bir bilgi nesnesi olarak ortaya çıkması bu süreçte temel önemdedir (Foucault, 2013, s.41, 57-58; Senellart, 2013, s.335). On sekizinci yüzyıldan itibaren modern bilimlerin bilgi üretim süreçlerinde insan ve davranışları çeşitli hesaplama, çözümleme ve düşünsel çabanın, dolayısıyla özneleş[tir]menin etkilerine açılmıştır (Foucault, 2013, s.70-71).

Ancak modern özneleş[tir]me, insanın kendilik pratiklerinde; yani varlığına ve davranışlarına yüklediği anlamda ve değerde belirli bir farklılık olmadan gerçekleşmez. Dolayısıyla özneleş[tir]me öznenin bir çeşit kabullenmesiyle, hem insanın tutumlarını yönlendirmesini hem de yönlendirilmesini içerir (Foucault 1988, s.13, 2011d). Burada müdahale, nüfus üzerinden elde edilen verilerin gösterdiği normallerden yani bireylerin değer sistemlerinden hareketle, gerçeklik öğesindeki kabul edilebilir sınırları saptamak ve kimi istençleri, arzuyu desteklemek, çoğaltmak suretiyle gerçekleşir (Foucault, 2013, s.67). Foucault'nun bu müdahaleyi üreten "bir dizi mekanizma ve usul olarak" tanımladığı modern iktidar, bu süreçte gerçekleşen "bilme [savoir] etkileri" nin üretimiyle ilgilenir (Foucault, 2013, s.4-5). Modern özneleş[tir]meyi mümkün hale getiren pratikler bütünü, bu bağlamda yönetimsellik analizi içerisinde "dispozitif" olarak tanımlanan şeyi oluşturur (Foucault, 2011f, s.118). Bu noktada milieu anahtar bir kavram olarak ortaya çımaktadır: Milieu bir varoluşu düzenlemeye yönelen yönetimsel iktidar modelinin stratejik pratiklerinin, dolayısıyla dispozitiflerin müdahale alanı olarak tanımlanmıştır.

Birlikte var olma sorunu olarak ele alınabilecek "şehir sorunu" yönetimselliğin kalbindedir ki iktidar mekanizmalarının üzerinde çalıştı̆̆ milieu, bu perspektifte kentsel mekânı karşılamaktadır (Foucault, 2013, s. 67). Bu çerçevede şu çıkarımı yapmak mümkündür: Modern iktidarın öznesi ve nesnesi nüfus, en önemli mekanizması da modern özneleş[tir]medir (Foucault, 2013, s.12). Dolayısıyla milieu olarak ele alınan mekânda özne ya da nesne değil, özel tarihsel gerekliliklerin koşullandırdığı pratikler bütünü belirleyicidir (Foucault, 2011d). Burada iktidar pratikleri olarak dispozitifler; söylemler, teoriler, mekân düzenlemeleri, kent planları, mimari biçimler, stratejik kararlar, yasalar, ahlaki önermelerden oluşan genel bir perspektifte işlerken, aynı zamanda bu unsurlar arasındaki ilişkiler ağıdır (Foucault, 2011f, s.118).

Foucault düşüncesinde özneleș,tir]meyi mümkün hale getiren bu manipülasyon, insan ile coğrafi, iklimsel ve fiziksel bir ortamının [milieu] iç içe geçmesi, kesişmesinde temellenmektedir (Foucault, 2013, s.25). Bu bağlamda ortama [milieu] müdahale, insanın değer sistemine, dolayısıyla fiziksel ve ahlaki 
varoluşuna müdahale demektir. Foucault'ya göre on sekizinci yüzyıldan itibaren insanın değerler sistemi, yaşam ortamı [milieu] üzerinden yönetim mekanizmalarına bu süreçler ve bileşenler aracillğıyla dâhil olmuştur (Foucault, 2011b, s.233; 2011d, s.354).

\section{Ortam: Nesne ya da Özneden Değerler ve Pratiklere}

Milieu kavramına ait teorik içerik aracılığıyla, merkezi bir oluşum önsezisiyle beraber ortaya çıkan kategorilerin karşısında, saf bir ilişkiler sistemine ait bir mekân kavrayışı ortaya konulabilmiştir. Bu içeriği üreten temel kavram ve düşüncelerden hareketle ortam, değerler tarafından yönlendirilen çeşitli eğilimlerin yapılandırdığı koşullar olarak ele alınmaktadır. Bu tanım bağlamında, ortamın ilişkileri zamansal olarak pekişerek bir sıklık dayatmaktır ki ortamın kendi gücü/eylemi söz konusudur. Milieu ve özneleş[tir]meye ilişkin teorik çerçeve bir arada ele alındığında modern kentler, aynı zamanda ortamın eyleminin yönlendirildiği amaçlı müdahalelerin alanı olarak ortaya çıkmaktadır. Dolayısıyla yurtlanma olarak ele alınan milieu döngüsü, kentleşmeyle gelişen modern bir iktidar biçiminin mekanizmalarını temellendirmektedir. Bu bağlamda iktidarın işleyişinin bu döngülere ve güce dâhil olduğu kentsel süreçler ve teknikler toplamı modernleşme eşiği olarak ele alınabilmektedir (Şekil 1). Kentsel ortam olası bir sorunsallaştırmanın, nesneleşme ve özneleş[tir]menin gerçekleştiği mekân olarak tanımlanabilmektedir (Şekil 2). Tersten bir okumayla; özne, nesne, kavram ve fikirler kentsel ortamın ilişkisel kuvvetlerinin bir devamıdır. Bu kavrayışla birlikte, artık özneyi ve nesneyi ortamın dışında özel bir bakış noktası olarak konumlandırmak olanaksızdır. Aksine öznenin ve nesnenin aynı anda ve karşılıklı olarak birbirlerini belirleyen ilişkisi ortaya konulmuş; insan ve çevre arasındaki bağlılaşık ilişki özne-nesne düzeyine taşınabilmiştir. 


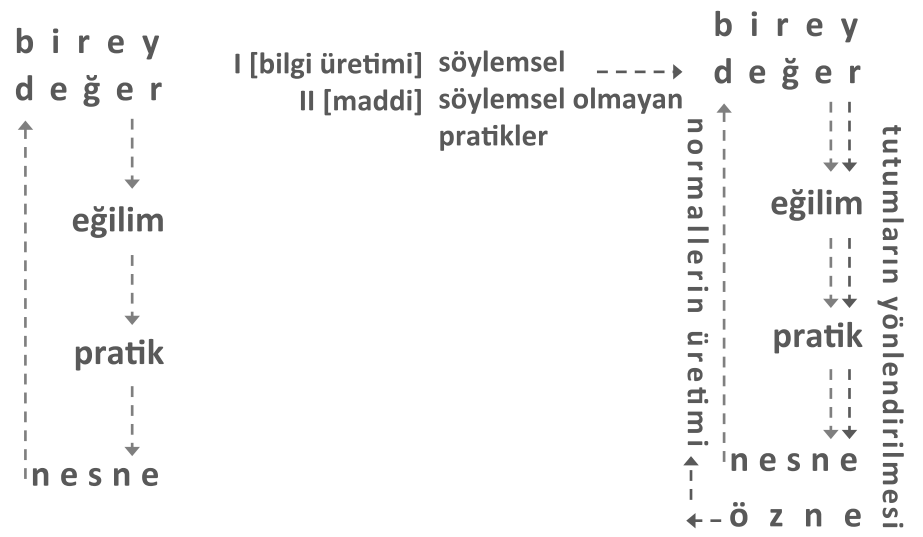

Şekil 1. (solda) İnsan ve çevre arasında değerler ve pratikler aracılığıyla kurulan varoluşsal ilişki ve (sağda) iktidar mekanizmalarının bu döngülere dahil olması; modernleşme eşiği.

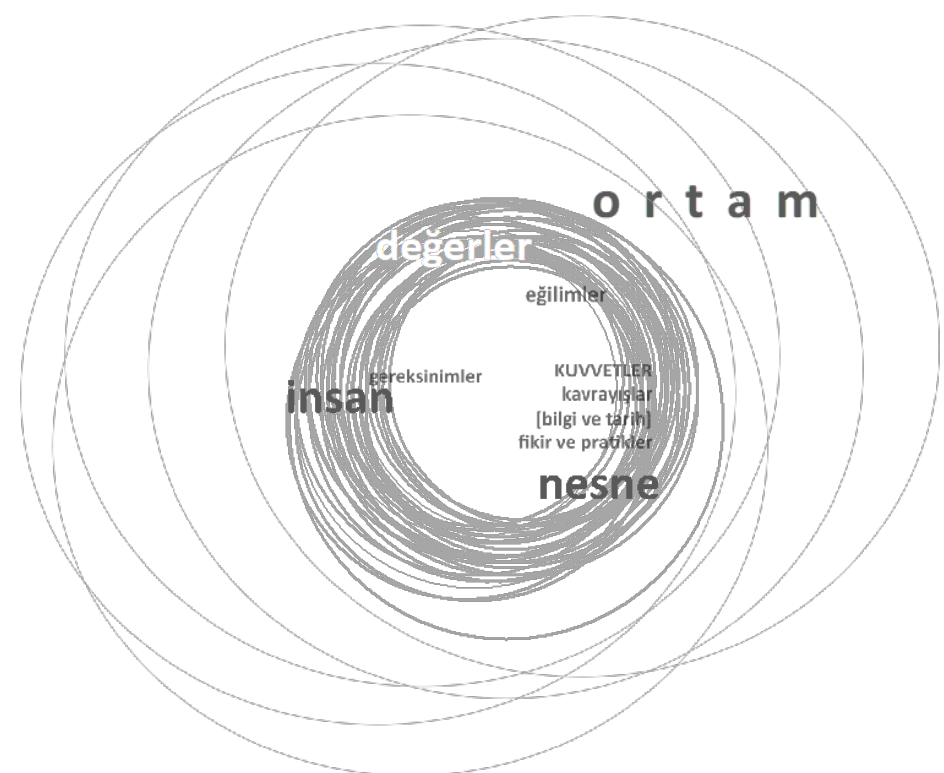

Şekil 2. İnsan ve çevre; özne ve nesne arasında değerler ve pratikler aracilığıyla kurulan varoluşsal ilişkinin oluşturduğu mekân-zaman bloğunun diyagramatik anlatımı.

İnsan ve çevre, özne ve nesne arasındaki varoluşsal ilişkide sinırları bulanik hale getiren değerler [anlam] ve pratikler olarak belirlenebilmektedir ki modern kentler de bu düşüncenin dışında kalmaz. Günümüzde yönelimleri, dolayısıyla ilişkileri ortaya çıkaran daha genel bir perspektifte ekonomi, poli- 
tika, bilgi üretimi ve iktidar ilişkilerinin koşullandırdığı özel tarihsel gereksinimler ve biçimini belirleyen ise değer sistemleri olarak ortaya konulabilir. Bu bağlamda özneleş[tir]meye yönelik manipülasyonu mümkün hale getiren müdahalenin esasen değerler sistemine ve dolayısıyla anlama yönelik olduğu iddia edilebilmektedir.

Başka bir ifadeyle müdahale ortamın değerler sisteminden hareketle, kendilik pratiklerini manipüle etmek üzere gerçekleşmektedir. Öyle ki modern özneleş[tir]me sürecinde tarihsel koşulların gerekliliklerine yönelik sorunsallaştırılan kentsel unsurlar ve olaylar, insanın kentle ilgili anlam ve değer sisteminde bir farklılığı koşullandırabilmektedir. Bu bakış açısıyla birlikte ortam, müdahalenin hem dayanağı hem de alanı olarak ortaya çıkarken, bireylerin eğilimleri de yönlendirilebilmektedir.

$\mathrm{Bu}$ çerçevede tarihsel gerekliliklerin koşullandırdığı mekânla ilgili bilgi üretimleri, mekânsal düzenlemeler, üretim, yıkım, muhafaza ve yeniden inşa gibi pratiklerin değerleri ve dolayısıyla ortamı manipüle ederek özne ve nesneyi belirlemeye yönelik stratejik işlevleri söz konusudur. Bu bağlamda mekânsal pratikler dispozitif olarak ortaya çıkarken, insan da bu pratiklerin kendine nesne olarak aldığı kente, doğal ve yapılı çevreye belirli bir normatif sistem içinde anlam ve değer yükler ki pratikleri bu normlar üzerinden gerçekleşir. Ortamın eğilimleri belirlemeye yönelik bir müdahale alanı olarak tanımlanabildiği bu durumda kimi yapma biçimleri normal hale gelerek kentsel ortamı yapılandırır.

\section{Tasarım Pratiklerinin Üretimine Yönelik Performatif Bir Araç Olarak Ortam [Medium]}

Bu çalışmada ortam aracilığıyla özne ve nesne arasındaki bağlılaşık ilişki üzerine düşünme çabası, mimarlık alanında tasarım pratiğinin üretim olanağından ayrılmaz. Bu doğrultuda sınır-tutum ve ortam gücü arasındaki çekişmenin tasarım pratiklerinin aracı olabileceği bir yaklaşım geliştirilmektedir.

Bu bağlamda ilk olarak yeniden gündeme getirmek gerekir ki milieu kavrayışı içinde öznenin değerler sistemi ve eğilimleri bu alanı oluşturan kuvvetlerden biri olarak ortaya çıkmaktadır. İkinci olarak modern özneleş[tir]me süreci kendilik pratiklerini içerir ki tutumların yönlendirilmesinin karşısına öznellik arayışına yönelik pratikler yerleştirilebilmektedir. Burada amaç, hakikatin tarihsel olarak koşullandırıldığı ve kurulduğu düşünüldüğünde, bu hakikatin çizdiği sınırların dışında yaratıcı pratiklerin olanağını ortaya koymaktır. Bu bağlamda ortam koşullarında öznellik; ortamın normallerine yönelik 
eleştirinin tesis edilmesi ve öznenin kendilik pratikleri üzerine düşünmesi anlamında sınır-tutumun üretimi olarak değerlendirilebilmektedir. Dolayısıyla yönetimsel mekanizmaların dolaylı olarak dayattığı normatif yapıdan, yeni bir takım normlar üreterek değil, eleştirel bir tutumla sıyrılan pratikler öznel deneyimin üretimi için olanaktır. Bu arayışla birlikte ortam, öznenin tarihsel eleştirel tutumunun nesnesi olarak ele alınabilmektedir.

Öte yandan öznelliğin üretimi; böyle bir tutumu koşullandırabilecek değerlerin ortamda var olmasıyla doğrudan ilişkilidir. Burada değer, milieu kavrayışından hareketle, kentsel ortamı yapılandıran özel ilişki kurma biçimlerini aktaran ve artık kendi eğilimlerine sahip unsurların niteliğidir -ki şimdinin hakikatini üretmeye yönelik kurulan bir tarihin sürekliliğine uygunluk anlamında kullanılmamaktadır-. Bu anlamda içinde barındırdığı kuvvetler ve olay çokluğu ile sürekli yapılandırılmakta olan ve aynı zamanda ortamı yapılandıran oluşumlar değer olarak ele alınmaktadır. Birer oluşum olarak ele alındığında mekânsal unsurlar, bu bağlamda artsüremli ve özneyle bağlllaşık ilişkisi temelinde eşsüremli olarak fiziksel sınırlarının ötesine genişletilmektedir. Dolayısıyla mimari nesne varlık kategorisi olmanın ötesinde, ortamin heterojen ilişki kurma biçimlerini kristalize etmesi nedeniyle değer olarak ele alınmaktadır. Bu bağlamda ortam, mekânsal unsurların yalnız başına değil, aksine bir birliktelik içinde değerlendirildiği bir mekân kavrayışıdır ki ortam gücü varlıktan ziyade, bu ilişkiselliğe bağımlıdır.

$\mathrm{Bu}$ yaklaşımla birlikte mimarlık nesnesinin biçimsel sınırlarını hem mekâna hem de zamana yayılırken düşünmek mümkündür. Böylece değer tartışması içinde nesnenin yalnızca kendi özellikleri; söz gelimi işlev, biçim vb. değil ortamla ve dolayısıyla özneyle kurduğu anlamlı ilişki biçimleri önemli hale gelir. Bu nedenle organik ya da yönetimsel mekanizmaların döngülere dâhil olması anlamında inorganik olsun, üretici potansiyellere sahip olan unsurlar değer olarak ortaya konulabilmektedir. Bu bağlamda coğrafi özellikler, topolojik veriler ve bu verilerin belirlediği kimi yapma biçimleri, malzeme ve teknik gibi kültüre özel pratikler zamansal süreçte yurtlanma düzeylerini; ifade gücünü, bilindik yolları (daireyi) üretmektedir. Öte yandan modern pratikler; planlama, büyük tarihi sosyal/siyasal değişimlere ve de özel tarihsel gerekliliklere yönelik cevaplar, yeni döngüler üreterek değerleri heterojen hale getirebilmektedir.

Bu bağlamda bir değer tanımı, Rossi'nin (2006) "ifade yapıları" ve "geçici öğeler" olarak tanımladığı, "olağan" ve "zamansız" kategorilerinin önemini yitirmesine neden olur. Bu kavrayışla birlikte kimi gereksinimlere yönelik 
üretilen yapı, mimari niteliği kadar zamansallığı barındırdığı için değer olarak ele alınabilmektedir. Bu bağlamda zamanın 'bozucu' etkisi olan harabe, patina gibi izler ortamın özel bileşenlerini ve zamansallığını işaret eden oluşumlardır. Daha genel bir perspektifte dışardan dayatılan unsurlar, ortam içinde yeniden kodlanabilir ki biçim, yapım tekniği gibi özneyle kurulan anlamlı bir ilişki üretebilirdir. Öte yandan modern bir mekânsal pratik olan planlama, gelecekteki eğilimleri belirlemeye yönelen önemli bir dispozitif olarak çalışırken, aynı zamanda yükseklik, gabari, dizi oluşturmak gibi hareket tekrarları üreterek unsurların eşsüremli ilişkilerini düzenleyebilir, bu ilişkiler zamansal olarak pekişerek ortamın varoluşsal döngüleri haline gelebilmektedir. Ortamın çeşitli kuvvetlerinin olayın tekil rastlantısında belirdiği, bu bağlamda öznenin sınır-tutumunu işaret eden tasarım nesnesi bir oluşum ve değer olarak ele alınabilmektedir.

Bu çerçevede kentsel ortamlar, zamansal süreçte kendisine şekil veren modern ya da geleneksel- bir dizi rejime dâhil olur ki uyum ya da saflıkla tanımlanamaz. Dolayısıyla kentler, Deleuze ve Guattari'nin düşüncelerinden hareketle, türdeş bir mekân-zamanda değil, heterojen katmanlar arasında çalışan çoğul ortamlar olarak ele alınabilmektedir (Şekil 3). Bu bağlamda kentsel ortamın heterojenliği yeni değerlerin üretimi için kendiliğinden bir hareket, gerilim ve etkileşimi içerir (Şekil 4) ki bilindik yollar ortamları kat eden kaçış-çizgilerini üretir (Şekil 5).

Böylece kentsel ortamın onu tanımlamaya ve sinırlandırmaya çalışan bağa karşı kendi ilişkisel çeşitliliği ortaya konulabilmektedir. Ortamın değerler açısından heterojenliğinin fikir ve pratiklerin çeşitliliğini öncelediği, bu bağlamda özneleş[tir]me süreçleri içinde normal kabul edilmiş pratiklere karşı eğilimleri çoğalttığı bir bakış açısı ortaya konulabilmektedir.

Değer olarak ele alınan unsurların sürdürülme gerekliliği paradoksal biçimde bu noktada ortaya çımaktadır: Çoğul ortamların biraradalığı olarak kent, herhangi bir bilgi ya da iktidar sisteminin tamamıla elde edemeyeceği bir şeydir ki aynı zamanda iktidar pratiklerine için de bir sınır oluşturmaktadır. Bu çerçevede hakikat kurucu olarak işlev gören bir "Tarih" söyleminin sürekliliğini kuran stratejik değer kavrayışına karşlık, Foucault'nun (2011c, s.220) "karşı-hafıza" olarak tanımladığı soybilimsel yöntemin aracı olabilecek bir değer tanımı mümkün olmaktadır. Öznelliği ve tasarım pratiklerini koşullandıran bu değer tanımıyla, ortam sadece fiziksel değil bilişsel bir süreç olarak ele alınabilmektedir. 


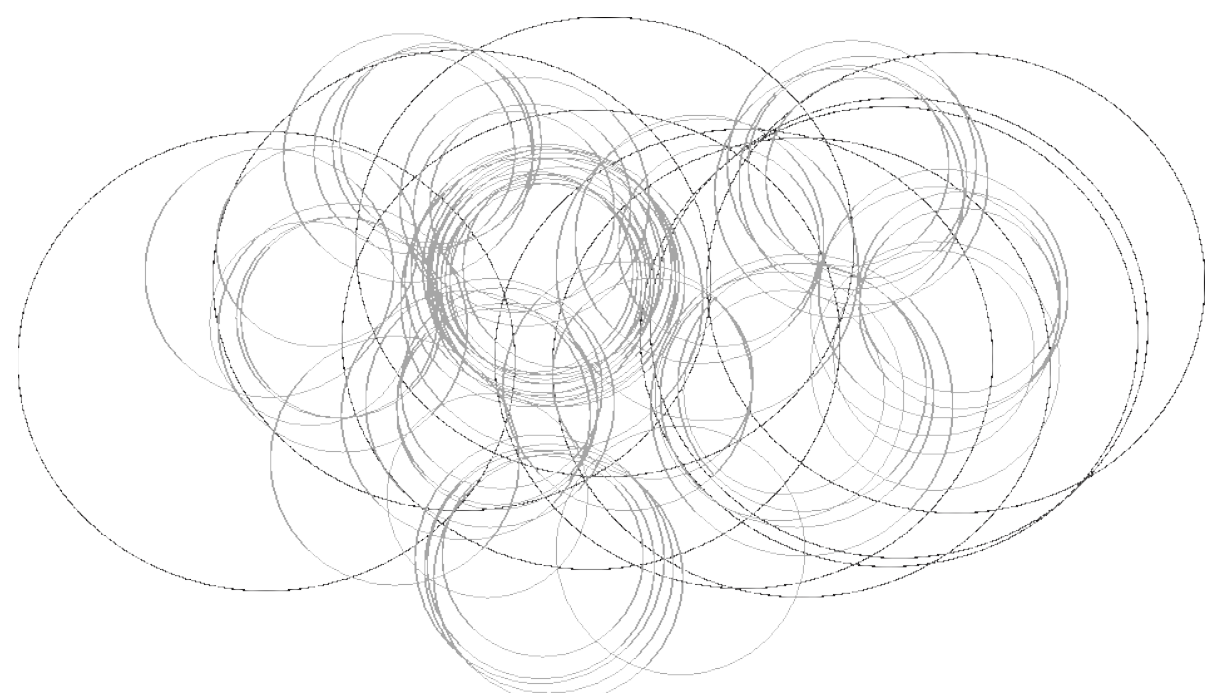

Şekil 3. Heterojen mekân-zamanların bir arada olduğu kentsel ortam diyagramı.

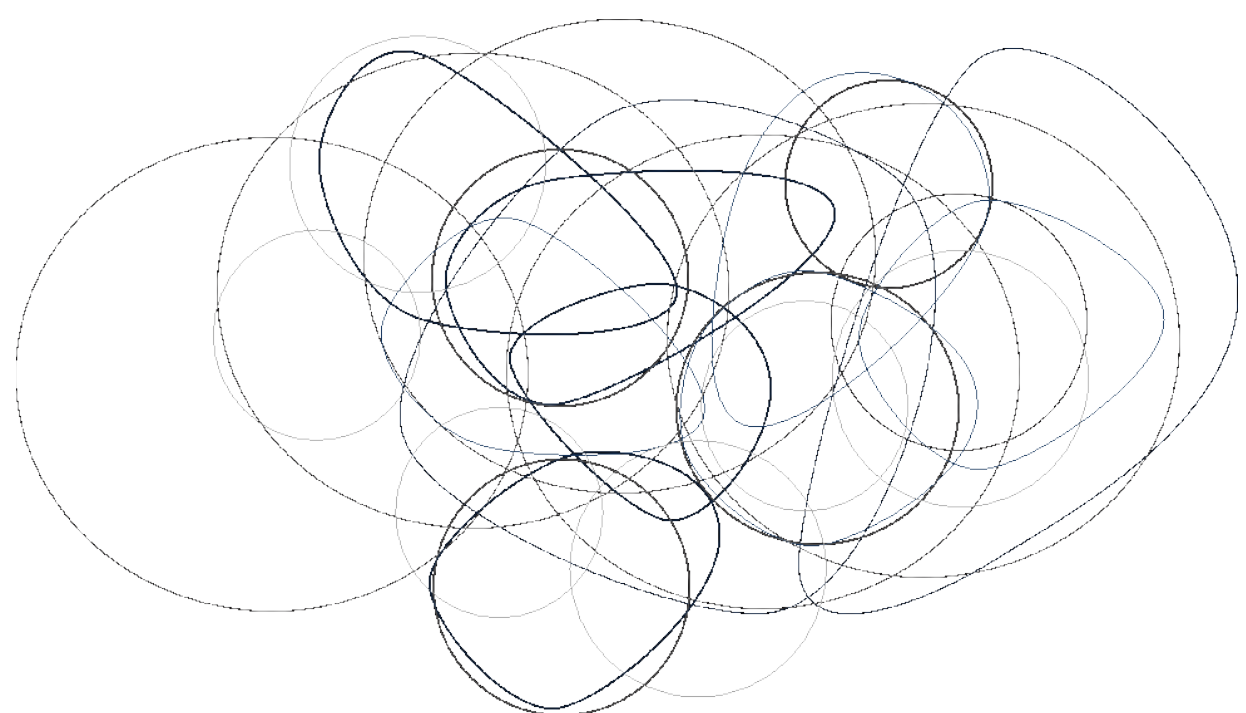

Şekil 4. Heterojen mekân-zamanlar arasında gerilim ve etkileşimin diyagramatik anlatimi. 


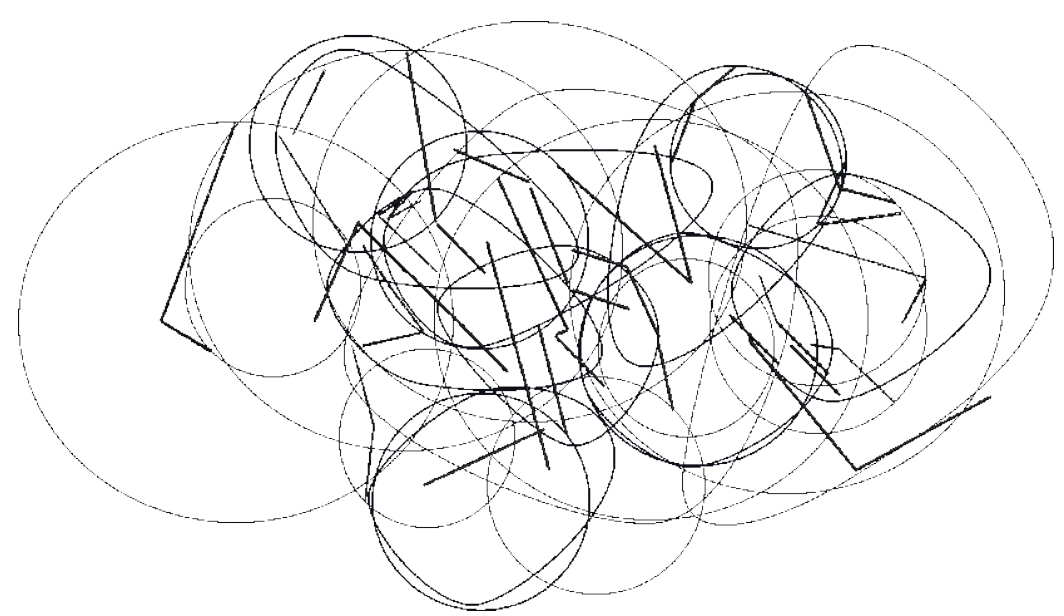

Şekil 5. Kentsel ortamın heterojen katmanlarını kat eden oluşumların üretiminin diyagramatik anlatımı.

\section{Ortam: Motivasyon ve Manipülasyona Yönelen Çekişmenin Alanı}

Mimarlık üzerinden geliştirilen özneleş[tir]me ve öznellik paradoksu, bu çalışmanın kavramsal modelinin içeriğini de belirlemiştir. Bu bağlamda ele alınan değer tanımı aracılığıyla ortamı hem manipülasyon durumuna hem de motivasyon potansiyeline yaklaştıran çatışkılı [antinomy] kuvvetler ortaya konulmaktadır. Dolayısıyla kentlerin olası pratikler üzerindeki eylemini, ortam değerleri ve özne ile ilişkili olarak çift yönlü ve tersinebilirdir.

Mimarlık bilgi alanında, mimarlığın nesnesinin varlık kategorilerinden kente ve alan koşullarına doğru genişlediği kronolojik bir okuma, deneyimin dışında bir gerçeklik olarak mekân kavrayışına ilişkin bakış açısı değişimi yaratmış ve ortam bu bağlamda ortaya konulmuştur. Bu anlamda bir paradigma değişiminin temsili olarak sunulan Koolhaas (1994) ve Manhattan okuması, ortam eyleminin çok güçlü olduğu kentlerin dahi öznenin performansı içinde çoğaltılabildiği, böylece yeniden-üretilebildiği bir pratik biçiminin örneğidir.

Izgara kent planına sahip Manhattan'ın doğası olarak "gösterge ve küre" [needle and globe] kavramsallaştırması öznel bir kent sorunsallaştırmasının kavramsal araçlarıdır. Maksimum iç hacmi en küçük harici dış katmanla kaplayan "küre" nesneleri, insanları, ikonografi ve sembolleri gelişi güzel kavrayacak bir kapasiteye; gösterge ise izgara içinde yeri işaretlemek için en ince ve en az hacme sahiptir. Koolhaas'a göre ancak bu sayede Manhattan birbiriyle yarışan bir olaylar mozaiği haline gelmektedir (Koolhaas, 1994, s.18-20, s.100). Bu dü- 
şünsel çaba yeni bir pratiğin üretim stratejisini belirler: Koolhaas, Manhattan'ını daha fazla kontrol alanına bölerek üreten ızgara sistemin aynılaştıran bütünlüğü içinde, azami birim olan bir tekil bloğu diğerinden ayıran stratejileri "ihlal" olarak tanımlamıştır (Stoppani, 2006, s.155).

Bu ilişkisel perspektifte ortam olarak kent; Foucault'nun (2011c, s.210) değişiyle üzerine çalışılan bir etkinliğin, dikkatin ve bilginin nesnesidir. Bu bağlamda motivasyon, ortama yeni bir ilişkiyi üretmek üzere yönelmekle ilişkilidir. Bu eğilimler özneyi işaret etmektedir; ancak ortam gücünün mevcut olduğu koşullarla ilişkilenmeye çalıştığımızda, ortamın eylemi her zaman kendisini dayatacaktır. Bu direnç, bu yaklaşım içinde aynı zamanda bir olanaktır. Ortamın sunduğu somut ve soyut araçları ya da başka bir deyişle sınırlılıkları, özne kendi araçlarıyla birleştirdiğinde yaratım anlamında yeni olanın üretim olanağı doğar. Bu bir tasarım pratiğidir; hem ortama özgüdür hem farkın üretimidir; bir ortamın öznede yeniden kurulmasıdır.

Tersten bir okumayla ortam, diyagramatik doğaya sahip bir gerçekleştirici olarak ele alınabilmektedir ki ortam gücü çeşitli pratiklerle yüzeye çıabilmektedir. Rossi'nin (2006) "Şehir" olarak kavramsallaştırdığı ve T. Stoppani'nin (2006) "Venedik hassasiyeti" [The chorality of Venice] olarak tanımladığı şey; Canaletto'nun 1740'larda yaptığı hayali Venedik manzarasında, Kazuhiro Murayama'nın 2001 yılında Londra, Architectural Association'daki "Glass Venice" in üretiminde ya da Asymptote'un 2004 yılında dokuzuncu Venedik Mimarlık Bienali'ndeki "Metamorph" unda analojik olarak üretilmeye devam eder (Stoppani, 2006, s.175), (Şekil 6).

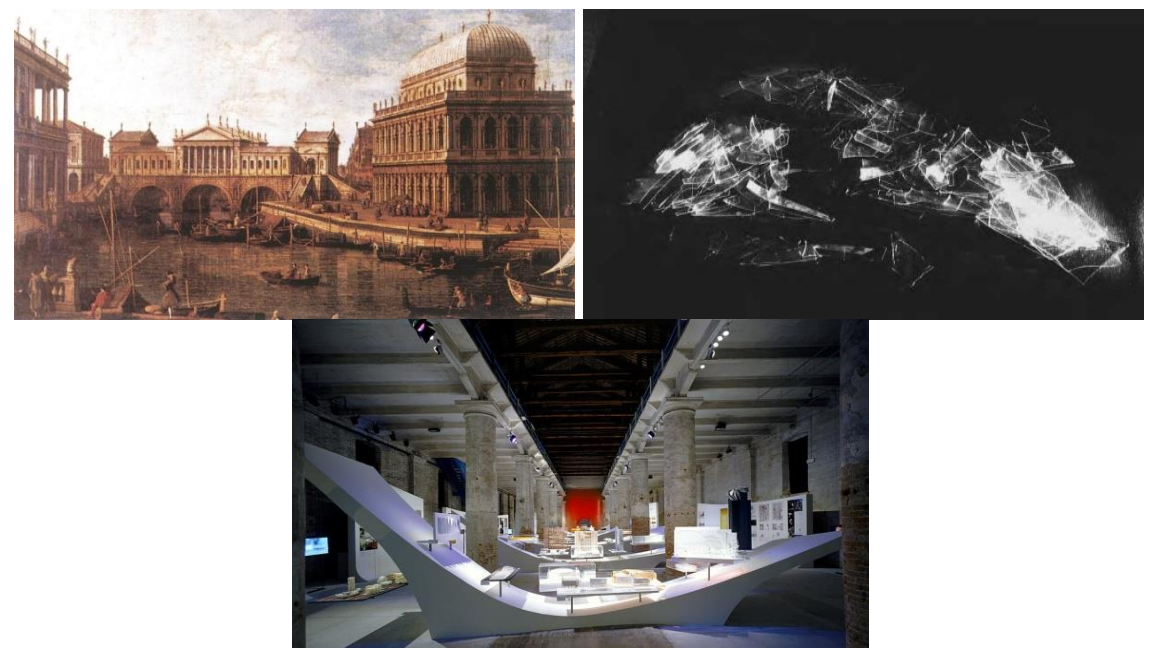

Şekil 6. Kentsel bir ortamın analojik olarak öznede kurulması 
(solda) Canaletto, 1743, (Giovanni Antonio Canal, Canaletto Gallery, (29.12.2017) https://www.canalettogallery.org/The-Rialto-Bridge-Venice.htm (sağda) Kazuhiro Murayama, "Glass Venice”, 2001, (Stoppani, 2006) (altta) Asymptote, H. Rashid ve L. Anne Couture, Metamorph, Venedik Bienali, 2004 (Asymptote Architecture, Asymptote Arc. (29.12.2017) https://www.asymptote.net/metamorph-slideshow?lightbox=i51cks

Öte yandan stratejik pratikler ve normal haline gelen yapma biçimleriyle ortamı bir manipülasyon alanı olarak ortaya çıkaran kuvvetleri, ekonomik değer üretiminin koşullandırdığını iddia etmek mümkündür. On sekizinci yüzyıldan itibaren kentleşme ve 'modernleş[tir]me' eğilimlerinin etkisiyle dolaşımlara açılma zorunluluğu ve devamında yirminci yüzyılın ikinci yarısında kapitalistleşme süreçleriyle birlikte sermayenin genişlemesi gerekliliği, değişim ve korumaya ilişkin kimi kavrayışları koşullandırmaktadır.

Bu tarihsel perspektifte mekânsal değişime yönelik arzu, ortamın varoluşsal ilişkilerini yok eden yıkım gibi stratejik kararların gerekçesi ve yeni norm üretiminin etkili bir aracı olarak ortaya çımaktadır. Bu stratejik müdahalelerin ortam için ortaya çıardığı hayati sorun, fiziksel sınırlarına çekilme, yani bir unsurun etkileşim halinde olan çeşitli kuvvetlerle ve diğer unsurlarla ilişkisinin zayıflaması, tekil hale gelmesi olarak belirlenebilir. Ortam söz konusu olduğunda, varoluş ile varlık arasındaki mesafenin arttığı böyle bir durumda unsurların önemli kapasitesi azalır. Bu durum aynı zamanda nesneyi güçsüz kılar ki kolayca yıkılabilmesinin de nedeni haline gelir. Bu bağlamda güçlü zamansal ilişkilere sahip tarihi kentlerin dahi ortam gücü çözünebilmekte, ortam türdeş hale gelebilmektedir. Dolayısıyla normatif değerler üzerinden gelişen pratiklerin sonucunda statik ve çözülmüş konfigürasyonlar ortamı yapılandırabilmektedir (Şekil 7).

Aynı süreçte tarihi değere sahip olduğu ve sürdürülmesi gerekliliği konusunda toplumsal bir hassasiyetin ortaya çıktığı unsurlar, 'muhafaza' pratikleriyle birlikte fiziksel sınırlarına çekilerek, Rossi' nin 'patolojik' olarak tanımladığ1 unsurlara dönüşebilmektedir (Rossi, 2006, s.24-29; Hays, 2015, s.34). Dolayısıyla bu unsurların gelecekteki oluşlar üzerinde etki ve tasarım pratikleri içinde araç olma potansiyeli azalır ki bu müdahalelerde ortaya çkan temel sorun değer kategorisiyle ilişkilidir. Bu pratiklerle yaşamın dışına itilen nesne, ortamın varoluşsal ilişkilerinin dışında aynen üretime tabi kalabilmektedir. Böyle bir üretimin zamana ve mekâna bağlı olmayan, bu bağlamda 'jenerik' hale gelen özelliği; öznenin duygulanımlarını, özel karşılaşmalarını olanaksız hale getirir. Bu durum artsüremli zaman algısını etkileyerek, tasarım 
pratiğinin kentle analojisi kurularak tasarlanabileceği potansiyellerini de engelleyebilmektedir.

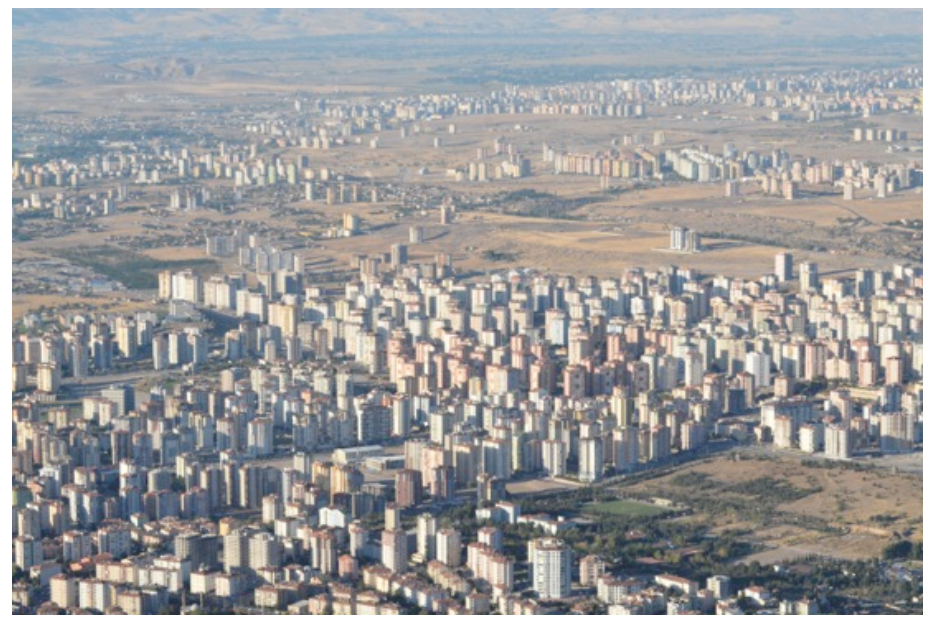

Şekil 7. Günümüz kentlerini yapılandıran nokta-blok (+yol) konfigürasyonu (Kayseri, 2016).

Ortamın bağlılaşık ilişkisi temelinde, öznenin değerler sistemine varoluşsal bir müdahale olarak bu pratikler, biçimlendirici yurtlanma ve özneleş[tir]me düzeylerinde çalışır. Bu anlamda güçten düşen, yaratma olanaksızlı̆̆ yaşayan tarihi kentlerin bir özelliği, önceden ve ortam dışında yapılmış olanı dayanak alma zorunluluğu olarak ortaya çıkmaktadır. Geçmişten gelen biçimler ya da 'tarih' temalı aynen üretimlerin bu bağlamda ortaya çıkması muhtemeldir. Böyle bir durumda değerli olanı yalnızca öznenin söylemi ya da nesnenin niteliği belirler ki iktidar ve özne konumlarıyla doğrudan ilişkilenebilmektedir. Dolayısıyla hakikat rejiminin üretimine yönelik stratejik olarak güçlü mekânsal pratiklerdir. Ortamın unsurlarının sürdürülemediği bu durumda, küresel kapitalist sistemin dayattı̆̆ değişim baskısının unsurları önce ayrıştıran ve sonra eşitleyen etkileri benzer fiziksel özelliklere sahip kentsel yapılanmalar, 'aynılaşma' gibi güncel sonuçları ortaya çıkarmaktadır.

Mekânsal ilişkilerin bağlayıcılığının yokluğunda, önemli olma kapasitesine sahip olamayan ilişkisiz parçaların yan yana olduğu bir kentsel ortamda tekil unsurlar; büyüklük, yükseklik, malzeme, renk gibi nesneden ya da tasarımcı öznenin özel konumdan kaynaklanan biçim üretimi etkisiyle -'efekt'var olur. Fark, yalnızca biçim arayışına dönüştügü noktada, öznelliğin yerini "kontrolsüz mimari egonun sergilenmesi" anlamında "teşhircilik" alır (Stoppani, 2006, s.159). Ancak böyle bir durumda özne ayrıcalıklı bir konuma geçer. 
Buradan hareketle diyebiliriz ki yıkım, tekillik, jenerik üretim, hassasiyet yokluğu, aynılaşma, efekt, öznenin özel konumu, dolayısıyla eğilimleri belirlemeye yönelik manipülasyon kentsel ortamın türdeş bir mekân-zamanda çalışmasıyla ilişkilidir.

Diğer taraftan hızlı değişim koşullarıyla birlikte gelen sorunlar, değerlerin ve oluşum olarak mekânsal unsurların sürdürülebildiği kentsel ortamlarda tasarım pratikleri içinde zaman, geçmiş, geçicilik ve yeni gibi kavramlara bakış açısı değişimleri yaratabilmektedir. Bu bağlamda muhafaza pratiklerinin ötesinde, geçmişi güncele doğru genişleterek, oluşan etkileşimi ve gerilimi tasarım fikri olarak ele alan yaklaşımlar ek, ekleme, adaptasyon ve genişletme [extension] gibi pratikler ortaya çıkmaktadır. Bu bağlamda ortama genişleyen mimari nesne, yeni bir mimarlık varoluşunun, pratiğinin konusu haline gelmiştir.

Bu kapsamda Architectural Record (2012) dergisinde, motivasyonunu farklı zamanlarla ilişki kurmaktan alan tasarım pratikleri tartışılmıştır. Bu pratiklerden biri olan David Chipperfield ve Julian Harrap tasarımı Berlin Neues müzesi, geleneksel anlamda restorasyonla tanımlanamayacak bir içeriğe ve deneyim olanağına sahip bir üretim biçimi olarak değerlendirilmiştir. Pailos'a (2012) göre, müzeyi önceki modellerden ayıran fikrin kaynağ 1 "yankı" [echo] yaklaşımıdır. Yankı olarak tanımlanan ve gücünü gelecekten alan şey saf formdaki orijinalin geri dönüşümü değildir, daha ziyade orijinalinden ayrılarak zamana transfer edilen bir şeydir. Bu geri dönüş, şimdiki zamanın parçası olarak kolayca yerleştirilemeyen zamansallık ruhunun ayırıcı işaretini taşıyan orijinal bir "çatlak"tır (Pailos, 2012, s.45). Konu kapsamında tartışılan bir diğer proje New York High Line ise mimarlığın bilgi alanında temel bir yenilenme olarak değerlendirilmiştir. Lentz'e (2012) göre “uyarlanmış yeniden kullanım" [adaptive reuse], çağdaş mimarlığın genel bakış açısında eski yapıya yeni kullanım arzusu aracilığıyla zarar verildiği süreç olarak anlaşılırken, High Line ile terimin anlamı çağdaş mimarlık ve eski yapının birbirleri için karşılıklı adaptasyonu olarak değişmeye başlamıştır.

Bu bağlamda insanın bağlılaşık dünyasının en önemli bileşeni olan mekân üzerine düşünen mimarlıkta müdahalenin koşulunu değer olarak tarif edilen unsurlar üzerinden belirlemek ve bu değerleri pratikler içinde sürdürmenin stratejilerini geliştirmek bir tasarım motivasyonu olarak ortaya konulabilmektedir.

Ortam kavrayışıyla birlikte mekân, mevcut koşullar ile olası pratikler arasında bir deneyim alanı olarak ortaya çıkmaktadır. Dolayısıyla mimari tasarım yalnızca nesne üretim süreci değil, aynı zamanda öznel bir çabanın üretildiği düşünsel bir süreçtir. Bu süreçte sınırları aşmak üzere, ortam koşulları 
temsil edilebilir/yeniden-üretilebilir bir araçtır [medium] ki tarihsel sınırlar ifade gücüyle aşılabilirdir. Böylece mimari tasarım, yeni bir mekânsal deneyimin arayışı; ama aynı zamanda 'gerçek olan'ın çoğul hale geldiği performatif bir pratik olarak eleştirinin somut bir ifadesi olarak tanımlanabilmektedir.

\section{Sonuç}

Ortam [milieu] kavramsallaştırması aracılığıyla kentleri yapılandıran mekânsal pratiklere, mimarlık bilgisinin konvansiyonel kavrayışlarının dolayımıyla ilk anda sınırlı bir ilişki alanını düşündüren -mekân, yer [territory] vb.- ya da merkezi ve ikincil konumlar üreten -çevre, etraf, form, bina, anıt vb.- temel kavramları yerine, ilişkisel koşullara vurgu yapan kavramsal bir bakış açısıyla yaklaşmak mümkün olmuştur. Ortaya konulan ilişkisel perspektif mekânsal pratiklere, dolayısıyla mimarlığa yönelik ontolojik bir değerlendirmeyi beraberinde getirmektedir.

İktidar mekanizmalarının ürettiği 'bilme etkileri' içinde tarihsel olarak belirlenen bilgi ve yönlendirilen deneyim ve tutumlar aracıllğıyla yaşanan modern özneleş[tir]me perspektifinden ele alındığında, mimarlı̆̆ın bilgisi ve pratikleri de tüm bu ilişkiler yumağı içerisinde yer alır. Bu bağlamda mimarlık, kendilik pratiklerinin üretimini yönlendiren bir kuvvet alanı ve mimarlık nesnesi de özel tarihsel koşullar içinde hakikatin üretimine katılan ideolojik bir şeydir. Tam da bu nedenle tasarım değeri, pratiğin gerçeklikten izole olduğu bir durumla değil, aksine ortam değerleriyle güncel ve eleştirel bir ilişkiyi karşılayan sınır-tutumla ilişkilendirilmektedir. Bu bağlamda yönetimsellik çağında mimarlık bilgi alanın belirleyen geleneksel ya da modern konvansiyonlardan ziyade hem özneleş[tir]meye hem de öznellik ve tasarıma arayışına yönelik çeşitli pratiklerdir. Bu değerlendirme aynı zamanda modern kentlerin karmaşık koşullarına gönderme yapmaktadır.

Bu bağlamda mimari tasarımın araçları belirlenebilmektedir: Sınır-tutum -öznellik arayışı-, kentsel ortam gücü ve ikisi arasındaki gerilim ve etkileşim; çekişme. Ancak ortam koşullarında sınır-tutumu mümkün hale getirebilecek, insanın farklı bağlantılarının kaynağı olabilecek oluşumlar olarak mimari unsurların sürekliliği, hem ortam değerlerini hem de insanın 'kendiliğini' güçlendirmesi için gereklidir. Dolayısıyla insan ve çevre, özne ve nesnenin bağlılaşık ilişkisi temelinde tasarım pratiklerinin aracı olabilecek ortam değerlerine yönelik hassasiyet, müdahalenin koşulu olarak ortaya konulabilmektedir. Bu bağlamda mekânla ilişkili tüm pratikler; değerlere yönelik stratejik etkileriyle tartışılmalıdır. 
Bu bağlamda çalışmanın paradoksal sonucudur şudur: Deneyimi tarihsel olarak koşullandıran normatif sınırlarına karşı, tasarım pratiği anlamında bir çoğulluğu üretmek için daha fazla heterojenliğe ihtiyacımız vardır. Bu nedenle içinde bulunduğumuz tarihsel dönemin hızlı değişim koşullarında, başat değer olarak ortaya çıkan ekonomik değeri yaratmaya yönelik istekle normal haline gelen fikirlerden ve yapma biçimlerinden kaynaklanan kararları yeniden değerlendirme gerekliliği tasarım pratiklerinin üretim olanağı için hayatidir. Çünkü her bir kentsel ortam, zamansallığıyla kendini, kendilik pratiklerine dayatan değer sistemlerini, kodlar ve kuralları, ilişki kurma biçimlerini, dolayısıyla atmosferik koşulları taşır. Bu bağlamda kentsel ortamın insanlara verdiği şey, esasen insanların pratiklerinin bir sonucudur. 


\title{
Extended Abstract
}

\section{Urban Milieu as a Space of Manipulation and Motivation}

\author{
Duygu Ovacık Çoruh \\ Erciyes Üniversitesi \\ ORCID: 0000-0002-2584-5312
}

The concept of milieu in this study reflects a spatial conception based on a correlative relationship between human and the environment. Accordingly, space has been formed as a conceptual medium within this study. The strategic effects of spatial practices are assessed through the concept of milieu via the process of determining the historical boundaries of subjective experience, and architectural design practices are considered to be the potential for generating new experiences against those historical boundaries. The relational ontological approach developed in this context determined the theoretical content and method of this study.

The study is grounded in a paradigm shift that emerged in the architectural literature after the 1960s. Accordingly, Aldo Rossi's concept of 'city' in the work Reading the Late Avant-Garde by K. Michael Hays (2010/2015) was examined first. Then, the theoretical studies of Hays (2010/2017), which he generalized as a "new paradigm" and called "atmospheric architecture" formed after the 1990s, was reviewed. The relationship of architectural objects with other objects and subjects has been extended and associated to the concept of city and "field conditions" as noted by Stan Allen (1999; 2010/2017) since the 1960s.

On the other hand, the conceptual model of this study is derived from the concept of milieu, which, has a unique content in the history of science and philosophy. The content of milieu stresses a trans-individual area that is different compared to the category of environment (outside). Accordingly, Georges Canguilhem defined a correlative relationship between living creatures and their conditions with the "intermediary spaces" theory he developed in his lectures entitled Le Vivant et son Milieu (1954). Gilles Deleuze and Felix Guattari applied this correlative relationship approach to all categories

idealkent @ C Kent Araştırmaları Dergisi (Journal of Urban Studies)

http://idealkentdergisi.com

Geliş Tarihi Received Date: 19.06.2019 Kabul Tarihi Accepted Date: 31.12.2019 
including living creatures and objects in Capitalism and Schizophrenia 2. In addition, Michel Foucault used the concept of milieu in an analysis of 'governmentality' with regard to the concept of biopower reflected in his courses entitled Collège De France 1977-78. In this analysis, Foucault conceptualized a basic difference that emerged from examining space in direct relationship to modernization and urbanization through the concept of milieu that can be defined-from Foucault's perspective-as the field of interventions for the governmental practices that are likely to manipulate the tendencies of subjects.

The relational ontological approach of this study is developed from the modernist perspective reflected by Foucault in the Histoire de la Sexualite: L'usage des plaisirs (1988). This analysis referred to as 'subjectification' in the study, is related to the historical establishment of the experience. To make it clearer, according to this subjectification theory, subjects and objects simultaneously and mutually determine one another through values and practices. This theoretical framework, with regard to architectural literature and the concept of milieu, was assessed through the approach presented by the theory of modern subjectification.

What defines the categorical boundaries in the space regarded as milieu are the values and practices that can turn into normative concepts and which are related to determining the subjective practices; in other words, the historical boundaries of subjective experience. Accordingly, cities, as a living milieu of modern human, were reviewed as the spaces where possible problematization, objectification and subjectification have occurred under particular historical conditions.

However, this determination does not mean acceptance. Milieu is a reproducible spatial concept within design practices. Accordingly, the milieu examined in the production of a spatial practice was examined as a performative intermediary space where reality can be regenerated and reproduced against historical boundaries. This problematization, based on the aforementioned correlative relationship, means reflexivity over the subjective tendencies, which is a critical approach. Therefore, within the practices for discovering a new experience, milieu can emerge as the object related to the critical attitudes of the subject in historical terms.

Thus, an approach was presented to indicate that cities develop as a sort of experience in the design period, and that objects and subjects are mutually transformed by practices. With this approach, a new perception was formed in the architectural literature by the orientation of the subject and object to 
space, values and practices. In this regard, the conditions of spatial intervention and means of design practices were re-examined.

The milieu values have an effect in directing the practices based on this correlative relationship. The quality defined here as 'value' indicates the repeated forces of the milieu. While values form the cyclical elements of the milieu, they also act as the signs and affections which are the potential for creative 'lines of drift'. Therefore, there are relationships and emerging factors configured in the milieu. While architectural elements configure the milieu, they are reviewed as factors multiplying the forces to generate difference. Therefore, the action of milieu over possible practices is bidirectional and reversible. In other words, milieu is the area of a configurative force where the possible effects of problematization and awareness emerge, and it is the area of 'critical attitude' with the style of examining subjectivity in this study.

Moreover, such an approach implies spatial practices, in other words, an ontological evaluation regarding the field of architecture. It is claimed that strategic interventions are related to the concepts with the quality referred to as 'value'. Thus, spatial practices should be reassessed for their strategic effects regarding their values and subjectification. On the other hand, the action of milieu regarding the diverse values in the relevant process can become the driving force for different attitudes, meaning that the need to maintain actions, and the demands for sensitivity, are existential in this context.

Ultimately, the milieu that emerges as a performative intermediary space during the production of design practices is removed from the historical normative boundaries, and hence, from the strategic value categories that define our performance, by multiplying the current conditions. Thus, the 'reality' can be reproduced against the normative boundaries, since milieu is the medium for new practices and different configurations.

\section{Kaynakça/References}

Allen, S. (1999). Field conditions. Points and lines: Diagrams and projects for the city, New York, NY: Princeton Architectural Press.

Allen, S. (2017). Alan koşulları. (K. A. Sykes Ed.), Yeni bir gündem inşa etmek mimarlık kuramı 1993-2009 içinde (s. 109-123). (G. Akyürek, Çev.). İstanbul: Küre Yayınları.

Baird, G. (2004). Criticality' and its discontents - rising ambitions, expanding terrain, realism and utopianism. Harvard Design Magazine, Fall 2004/Winter 2005, 16-21. http://www.harvarddesignmagazine.org/issues/21 adresinden erişilmiştir. 
Ballantyne, A. (2010). Mimarlar için düşünürler 01: Deleuze ve Guattari. (R. Öğdül, Çev.). İstanbul: Yapı Endüstri Merkezi Yayınları. (Orijinal eserin yayın tarihi 2007).

Calinescu, M. (2011). Modernizm, avangard, dekadans, kitsch, postmodernizm. (S. Gürses, Çev.). İstanbul: Küre Yayınları. (Orijinal eserin yayın tarihi 1987).

Canguilhem, G. (2001). The living and its milieu. (J. Savage, Çev.). Grey Room, içinde (s.7-31). http://www.jstor.org/stable/1262564 adresinden erişilmiştir.

Chien, J. P. (2006). From animals to humans: Uexküll's umwelt as read by Lacan and Canguilhem. Concentric: Literary and Cultural Studies, 32(2), 45-69. http://www.concentric-literature.url.tw adresinden erişilmiştir.

Deleuze, G. ve Guattari, F. (1987). Capitalism and schizophrenia 2: A thousand plateaus. (B. Massumi, Çev.). Minneapolis, MN: University of Minnesota Press. (Orijinal eserin yayın tarihi 1980).

Foucault, M. (1988). Cinselliğin tarihi (Cilt 2). (H. Tufan, Çev.). İstanbul: Afa Yayınları. (Orijinal eserin yayın tarihi 1984).

Foucault, M. (2011a). Aydınlanma nedir? (F. Keskin Yay. haz.), Seçme yazılar 2: Özne ve iktidar içinde (s. 173-192). (O. Akınhay, Çev.). İstanbul: Ayrıntı Yayınları. (Orijinal eserin yayın tarihi 1994).

Foucault, M. (2011b). Bir özgürlük pratiği olarak kendilik kaygısı etiği. F. Keskin (Yay. haz.), Seçme yazılar 2: Özne ve iktidar içinde (s. 221-247). (O. Akınhay, Çev.). İstanbul: Ayrıntı Yayınları. (Orijinal eserin yayın tarihi 1994).

Foucault, M. (2011c). Etiğin soybilimi üzerine: Sürmekte olan çalışmaya ilişkin bir değerlendirme. F. Keskin (Yay. haz.), Seçme yazılar 2: Özne ve iktidar içinde (s. 193220). (O. Akınhay, Çev.). İstanbul: Ayrıntı Yayınları. (Orijinal eserin yayın tarihi 1994).

Foucault, M. (2011d). Foucault. F. Keskin (Yay. haz.), Seçme yazılar 2: Özne ve iktidar içinde (s. 349-354). (İ. Ergüden, Çev.). İstanbul: Ayrıntı Yayınları. (Orijinal eserin yayın tarihi 1994).

Foucault, M. (2011e). Hakikat kaygısı. F. Keskin (Yay. haz.), Seçme yazılar 2: Özne ve iktidar içinde (s. 83-97). (O. Akınhay, Çev.). İstanbul: Ayrıntı Yayınları. (Orijinal eserin yayın tarihi 1994).

Foucault, M. (2011f). Michel Foucault'nun oyunu. F. Keskin (Yay. haz.), Seçme yazılar 1: Entelektüelin siyasi işlevi içinde (s. 117-155). (O. Akınhay, Çev.). İstanbul: Ayrıntı Yayınları. (Orijinal eserin yayın tarihi 1994).

Foucault, M. (2011g). Nietzsche, soybilim, tarih. F. Keskin (Yay. haz.), Seçme yazılar 5: Felsefe sahnesi içinde (s. 230-253). (I. Ergüden, Çev.). İstanbul: Ayrıntı Yayınları. (Orijinal eserin yayın tarihi 1994).

Foucault, M. (2011h). Özne ve iktidar. F. Keskin (Yay. haz.), Seçme yazılar 2: Özne ve iktidar içinde (s. 57-82). (O. Akınhay, Çev.). İstanbul: Ayrıntı Yayınları. (Orijinal eserin yayın tarihi 1994).

Foucault, M. (2013). Güvenlik, toprak, nüfus, Collège De France dersleri (1977-1978). (F. Taylan, Çev.). İstanbul Bilgi Üniversitesi Yayınları. 
Hays, M. K. (2015). Mimarlı̆̆ın arzusu: Geçavangardı okumak. (V. Atmaca ve B. Demirhan, Çev.). İstanbul: Yapı Endüstri Merkezi Yayınları. (Orijinal eserin yayın tarihi 2010).

Hays, M. K. (2017). Sonsöz. K. A. Sykes (Ed.), Yeni bir gündem inşa etmek mimarlık kuramı 1993-2009 içinde (s. 439-442). (G. Akyürek, Çev.). İstanbul: Küre Yayınları. (Orijinal eserin yayın tarihi 2010).

Keskin, F. (2002). Problematization and games of truth: Michel Foucault's analytics of constitution of the subject in political Modernity. Yayımlanmamış doktora tezi, Graduate School of Arts and Sciences, Department of Philosophy, Columbia University, New York.

Koolhaas, R. (1994). Delirious New York A retroactive manifesto for Manhattan. New York, NY: The Monacelli Press.

Kwinter, S. (2002). Architecture of time, toward a theory of the event in Modernist culture. Londra, United Kingdom: MIT Press.

Lentz, L. C. (2012). Raise high the roof: Renovation, adaptation, addition. Architectural Record, 200, 56-60.

Lynn, G. (2017). Mimari eğrisellik: Kıvrılmış, esnek, bükülgen. (K. A. Sykes Ed.), Yeni bir gündem inşa etmek mimarlık kuramı 1993-2009 içinde (s. 29-56). (G. Akyürek, Çev.). İstanbul: Küre Yayınları. (Orijinal eserin yayın tarihi 2010).

Martin, R. (2017) Neye karşı eleştirel? Ütopyacı Bir gerçekliğe doğru. K. A. Sykes (Ed.), Yeni bir gündem inşa etmek mimarlık kuramı 1993-2009 içinde (s. 321-336). (G. Akyürek, Çev.). İstanbul: Küre Yayınları. (Orijinal eserin yayın tarihi 2010).

Megill, A. (2008). Aşırılı̆̆ın peygamberleri: Nietzsche, Heidegger, Foucault, Derrida. (T. Birkan, Çev.). İstanbul: Ayraç Kitabevi. (Orijinal eserin yayın tarihi 1985).

Pailos, J. O. (2012). Restoration redux: Renovation, adaptation, addition. Architectural Record, 200, 44-45.

Rossi, A. (2006). Şehrin mimarlı̆̆ı. (N. Gürbilek, Çev.). İstanbul: Kanat Yayınları. (Orijinal eserin yayın tarihi 1996).

Senellart, M. (2013). Derslerin bağlamı. Michel Foucault: Güvenlik, toprak, nüfus, Collège De France dersleri (1977-1978) içinde (s. 323-349). (F. Taylan, Çev.). İstanbul Bilgi Üniversitesi Yayınları.

Somol, R. ve Whiting, S. (2017). Doppler etkisi ve Modernizmin öteki ruh halleri üzerine düşünceler. (K. A. Sykes Ed.), Yeni bir gündem inşa etmek mimarlık kuramı 19932009 içinde (s. 175-178). (G. Akyürek, Çev.). İstanbul: Küre Yayınları. (Orijinal eserin yayın tarihi 2010).

Speaks, M. (2017). Tasarım zekası. (K. A. Sykes Ed.), Yeni bir gündem inşa etmek mimarlık kuramı 1993-2009 içinde (s. 189-200). (G. Akyürek, Çev.). İstanbul: Küre Yayınları. (Orijinal eserin yayın tarihi 2010).

Stoppani, T. (2006). The reversible city: Exhibition(ism), chorality, and tenderness in Manhattan and Venice. (C. Lindner Ed.), Urban space and cityscapes - perspectives from modern and contemporary culture (s. 155-175) içinde. New York, NY: Routledge. 
Sykes, K. A. (Ed.). (2017). Giriş. Yeni bir gündem inşa etmek mimarlık kuramı 1993-2009 içinde (s. 15-28). (G. Akyürek, Çev.). İstanbul: Küre Yayınları. (Orijinal eserin yayın tarihi 2010).

Tschumi, B. (1976). Theory: Architecture and transgression. Oppositions, winter 7, 5563. Cambridge: The MIT Press.

Türk Dil Kurumu. (2017). Türkçe sözlük. http://www.tdk.gov.tr/index.php?option=com_gts\&arama=gts\&guid=TDK.GTS.5bcaf349900a22.90175781 adresinden erişilmiştir.

Vidler, A. (1976). Introduction: Theory: Architecture and transgression. Oppositions, winter, 7, 55. Cambridge: The MIT Press. 